\title{
OPEN vB_BcM_Sam46 and vB_BcM_ Sam112, members of a new bacteriophage genus with unusual small terminase structure
}

\author{
Olesya A. Kazantseva ${ }^{\bowtie}$, Emma G. Piligrimova \& Andrey M. Shadrin $₫$ \\ One of the serious public health concerns is food contaminated with pathogens and their vital activity \\ products such as toxins. Bacillus cereus group of bacteria includes well-known pathogenic species \\ such as $B$. anthracis, B. cereus sensu stricto (ss), B. cytotoxicus and B. thuringiensis. In this report, \\ we describe the Bacillus phages vB_BcM_Sam46 and vB_BcM_Sam112 infecting species of this \\ group. Electron microscopic analyses indicated that phages Sam 46 and Sam 112 have the myovirus \\ morphotype. The genomes of Sam46 and Sam 112 comprise double-stranded DNA of 45,419 bp and \\ 45,037 bp in length, respectively, and have the same GC-content. The genome identity of Sam46 \\ and Sam 112 is $96.0 \%$, indicating that they belong to the same phage species. According to the \\ phylogenetic analysis, these phages form a distinct clade and may be members of a new phage genus, \\ for which we propose the name 'Samaravirus'. In addition, an interesting feature of the Sam 46 and \\ Sam112 phages is the unusual structure of their small terminase subunit containing N-terminal FtsK_ \\ gamma domain.
}

Bacteriophages, also known as phages, are viruses that infect bacteria. It is well established that phages are the most abundant biological organisms, with a total amount of about $10^{30}-10^{32}$ phage particles on the planet ${ }^{1}$. Bacteriophages are ubiquitous in all habitats of their prokaryotic hosts, including extreme ones ${ }^{2-5}$. Phages are known to play a significant role in biospheric processes. They are involved in global biogeochemical cycling (such as the carbon and nitrogen cycles) and ecology by regulating the abundance and composition of microbial communities $^{6-8}$. Bacteriophages are the important part of genetic exchange in the environment and actively influence microbial evolution by means of generalized, specialized and lateral transduction ${ }^{9,10}$. However, phages are of considerable interest not only for fundamental biology but also for medicine and biotechnology. On the one hand, bacteriophages are microbial predators and can be used as a preventive measure or treatment for bacterial infections, which are a serious hazard to both human health and activities such as agriculture, animal husbandry and food industry. This fact offers incredible prospects for R\&D projects and drug design based on phages and/ or their lytic proteins (endolysins and virion-associated peptidoglycan hydrolases) ${ }^{11}$. To date, phages have been applied as sources of diagnostic and genetic tools and as novel therapeutic agents ${ }^{12-14}$. On the other hand, it should be remembered that phage transduction is one of the mechanisms of horizontal gene transfer (HGT) between bacterial cells $s^{9,10}$. Therefore, bacteriophages can be potential sources of virulence factors and antibiotic resistance of bacteria ${ }^{15-17}$. Thereby, studying of phage diversity and role in the evolution and life of bacterial hosts is of great significance for improvement and extension of the scope of phage application, in particular, in medicine and biotechnology.

One of the serious public health concerns is food contaminated with pathogens and their vital activity products such as toxins. The Bacillus cereus group, equally well-known as B. cereus sensu lato (sl), is a group of Gram-positive spore-forming bacteria, which comprises genetically closely related species with rather broadspectrum pathogenicity. The most remarkable members of this group are B. anthracis, B. cereus sensu stricto (ss), $B$. cytotoxicus and B. thuringiensis. $B$. anthracis is an obligate pathogen and causes anthrax, an acute infectious disease that mainly infects livestock and wild ungulates, but anthrax outbreaks occur in humans annually and require constant monitoring and risk assessment ${ }^{18}$. B. cereus is an opportunistic pathogen and is associated with two types of foodborne poisonings, in particular, the diarrheal syndrome caused by enterotoxins and the emetic

Laboratory of Bacteriophage Biology, G.K. Skryabin Institute of Biochemistry and Physiology of Microorganisms, Pushchino Scientific Center for Biological Research of the Russian Academy of Sciences, Federal Research Center, 142290 Pushchino, Russia. ${ }^{\boxplus}$ email: olesyakazantseva@bk.ru; andrey2010s@gmail.com 
syndrome caused by the toxin cereulide ${ }^{19}$. B. cytotoxicus is the less studied species than those mentioned above inasmuch as it has been fairly recently described for the first time ${ }^{20}$. B. cytotoxicus is responsible for severe diarrheal disease due to production of its $c y t K 2$ variant of cytotoxin $\mathrm{K}$, which is able to cause necrotic enteritis ${ }^{21}$. Contamination of foodstuffs with spores and/or vegetative cells of both B. cereus and B. cytotoxicus poses a serious threat to public health and can cause extensive harm to food industry and agriculture. $B$. thuringiensis is referred to as an entomopathogenic species able to produce crystal insecticidal toxins ( $\delta$-endotoxins) ${ }^{22}$. This is why biopesticidal strains of $B$. thuringiensis have become widespread as microbiological biopesticides being the most environmentally friendly and safe for human health among insecticidal products available ${ }^{23,24}$. Nevertheless, the actual contribution of $B$. thuringiensis to the cases of poisoning is still highly contentious ${ }^{25,26}$.

Taking into account the major challenge of the emergence and spread of multi-drug resistant bacteria including pathogens of the $B$. cereus group ${ }^{27,28}$, it is apparent that phage therapy has the potential to become either an alternative or a supplement to the classical antibiotic treatments. However, the creation of effective phage-based preparations requires developing and maintaining the collections of carefully selected and well-studied bacteriophages acting on target pathogen species and strains.

In this study, we describe the newly isolated and characterized Bacillus phages vB_BcM_Sam46 and vB_ BcM_Sam 112 (abbreviated as Sam 46 and Sam112, respectively), which effectively infect members of the B. cereus group. Phages Sam 46 and Sam 112 have morphological characteristics typical of myoviruses. The genomes of Sam 46 and Sam 112 comprise double-stranded DNA, 45,419 bp and 45,037 bp in length, respectively, and the same GC-content. The genome identity of Sam 46 and Sam 112 is $96.0 \%$ indicating that they belong to the same phage species. According to the phylogenetic analysis, these phages form a distinct clade and may be members of a new phage genus. We propose to create a new bacteriophage genus called 'Samaravirus' to formally classify these phages.

\section{Materials and methods}

Bacterial strains and growth conditions. The bacterial strains used in this study were obtained from the All-Russian Collection of Microorganisms (VKM). Lysogeny broth (LB) and LB agar (1.5\% w/v and 0.75\% w/v) with $10 \mathrm{mM} \mathrm{CaCl}_{2}$ and $10 \mathrm{mM} \mathrm{MgCl}_{2}$ were used for bacterial and phage cultivation. All cultures were grown at $37^{\circ} \mathrm{C}$.

Phage isolation and propagation. Phages Sam46 and Sam 112 were isolated from soil samples collected in Samara, Russian Federation, and propagated on the sensitive strain B. cereus VKM B-370. The sensitive strain B. cereus VKM B-370 was grown in $10 \mathrm{ml}$ of LB broth with $10 \mathrm{mM} \mathrm{CaCl}_{2}$ and $10 \mathrm{mM} \mathrm{MgCl}_{2}$ to the optical density of 0.6 at $590 \mathrm{~nm}$. One gram of the soil sample was added to the cell culture and the mixture was incubated for $2 \mathrm{~h}$ at $37^{\circ} \mathrm{C}$ until optical density decreased. The obtained suspension was centrifuged for $10 \mathrm{~min}$ at $12,000 \mathrm{~g}$. After that, the lysate was mixed with $100 \mu \mathrm{l}$ of B. cereus VKM B-370 culture (OD590 of 0.35) and 1.5\% agar to the final agar concentration of $0.5 \%$. After gentle short-term vortexing, the mixture was poured into Petri dishes with previously prepared LB agar $(1.5 \%)$ and incubated overnight at $37^{\circ} \mathrm{C}$. Further, the separate plaques were transferred into $2 \mathrm{ml}$ of SM+ buffer [125 mM Tris- $\mathrm{HCl}, \mathrm{pH} 8.0 ; 100 \mathrm{mM} \mathrm{NaCl} ; 2.5 \mathrm{mM} \mathrm{MgSO}_{4} ; 0.01 \%$ gelatin; $10 \mathrm{mM} \mathrm{CaCl}_{2}$ ] and incubated overnight at $4{ }^{\circ} \mathrm{C}$ with shaking for phage extraction. The extracts of single plaques were centrifuged for $10 \mathrm{~min}$ at $12,000 \mathrm{~g}$, and $50 \mu \mathrm{l}$ of the supernatants were transferred into a 48 -well plate containing $500 \mu \mathrm{l}$ of $\mathrm{LB}$ broth (with additional $10 \mathrm{mM} \mathrm{CaCl}_{2}, 10 \mathrm{mM} \mathrm{MgCl}_{2}$ ) with $5 \mu \mathrm{l}$ of B. cereus VKM B-370 culture (OD590 0.6) and incubated for $16 \mathrm{~h}$ at $37^{\circ} \mathrm{C}$ until optical density decreased. The cultures with the lowest optical densities were transferred into $1.5 \mathrm{ml}$ Eppendorf tubes with $50 \mu \mathrm{l}$ of chloroform. The cell debris was removed by centrifugation for $10 \mathrm{~min}$ at $12,000 \mathrm{~g}$. The obtained lysates were titrated by serial dilutions. In order to exclude the presence of other phages with morphologically identical plaques, the extraction-titration cycles were repeated five times. Phage propagation and PEG 8,000 (polyethylene glycol) precipitation were performed as described previously ${ }^{29}$. The obtained high-titer phage sample was filtered through a $0.22 \mu \mathrm{m}$ sterile filter and stored at $4{ }^{\circ} \mathrm{C}$. Three $\mathrm{ml}$ of the high-titer preparation was subsequently used to prepare the final purified phage suspension by $\mathrm{CsCl}$ density gradient centrifugation (with preformed gradient of CsCl: $1.3 \mathrm{~g} / \mathrm{ml}, 1.4 \mathrm{~g} / \mathrm{ml}, 1.5 \mathrm{~g} /$ $\mathrm{ml}, 1.6 \mathrm{~g} / \mathrm{ml}$ and $1.7 \mathrm{~g} / \mathrm{ml}$ ). The purified suspension was ultimately used for transmission electron microscopy.

Host range determination. A host range test was performed using 32 strains of the $B$. cereus group as described previously ${ }^{29}$ with differences in incubation conditions (for $24 \mathrm{~h}$ at $37^{\circ} \mathrm{C}$ ).

Transmission electron microscopy. Phage suspension applied onto 400 mesh carbon-formvar coated copper grids was negatively stained with $1 \%$ uranyl acetate and subsequently analyzed using a JEM-100C (JEOL, Japan) transmission electron microscope at $80 \mathrm{kV}$ accelerating voltage. Images were taken on Kodak film SO-163 (Kodak, Cat. \# 74144, Hatfield, PA, USA). Phage particle dimensions were measured using ImageJ version $1.53 \mathrm{e}$ in relation to the scale bar generated from the microscope.

Genome sequencing, assembly and sequence analysis. Phage DNA was extracted using the standard phenol-chloroform extraction protocol described by Sambrook et al. ${ }^{30}$. Purified phage DNA was sequenced using Illumina with TruSeq library preparation technology. The de novo genome assembly was accomplished by SPAdes v.3.11.1 software ${ }^{31}$. Open reading frames (ORFs) were identified by RASTtk v.2.0 ${ }^{32}$. The putative functions were predicted using BLAST (NCBI) ${ }^{33}$ and $\mathrm{HHpred}^{34}$. The circular genome visualizations were created by BRIG software v. $0.95^{35}$. 
Sequence alignment analysis and Neighbor-Net network analysis. The accessions of the analyzed FtsK gamma domain were as follows: Sam46: QIQ61202.1, 11-70 aa; Sam112: QGF21705.1, 11-70 aa; B. cereus: SME41550.1, 727-786 aa; B. subtilis: WP_003231869, 721-780 aa; E. coli: NP_415410.1, 1266-1325 aa; L. lactis: WP_003129457.1, 693-752 aa; P. aeruginosa: ARG86759.1, 747-806 aa. The dataset sequence was used for alignment by MAFFT version 7 with default options ${ }^{36}$. Alignment data were manually trimmed and the aligned residues of the FtsK_gamma domain (60 aa in length) were used for the Neighbor-Net network analysis. The Neighbor-Net network tree was drawn by SplitTree4 v.4.16.1 ${ }^{37}$ with 1000 bootstrap replicates.

Comparative genomics. To assess the phylogenetic relationship of Sam46 and Sam112 to the known phages, ViPTree server version $1.9^{38}$ was used to generate a proteomic tree based on the genome-wide sequence similarities computed by tBLASTx. The linear comparison diagram showing the similarity between the most closely related phage genomes was visualized with the ViPTree server version $1.9^{38}$. The number of shared proteins was computed using the GET_HOMOLOGUES software v3.3.3 $33^{39}$ with the COGtriangles algorithm ${ }^{40}(-\mathrm{t} 0$ -C 75 -e). The compare_clusters.sh script from the GET_HOMOLOGUES package was used to produce a pangenome matrix showing the presence/absence of representatives of individual protein clusters in each genome. The matrix was then used to build a Maximum-likelihood tree with the GET_PHYLOMARKERS software package version 2.2.8.1 ${ }^{41}$. The resulting tree was rooted at the midpoint and visualized with FigTree v1.4.4 ${ }^{42}$.

Headful DNA analysis. The bacteriophage genome termini were identified based on the read occurrence frequency following the High Occurrence Read Termini theory ${ }^{43,44}$. Mapping the reads to the genome was carried out with the Bowtie 2 software tool v.2.3.4.3 $3^{45,46}$. The in silico results were experimentally confirmed using a standard restriction analysis ${ }^{47}$. The pac-site was determined by sequencing terminal DNA fragments obtained by the method of rapid amplification of genomic ends (RAGE) ${ }^{48}$, which is based on the principles of the $5^{\prime}$-Rapid amplification of cDNA ends ( $5^{\prime}$-RACE). For this purpose, the specific fragments suspected to contain the phage genome termini were extracted from electrophoresis gel after restriction analysis and used for a typical DNA tailing reaction by terminal transferase (New England Biolab, Cat. \# M0315L). Further, two PCRs were carried out consecutively using the TaqSE DNA polymerase (SibEnzyme, Cat. \# E314) and the pairs of oligonucleotides Fw-d(T)16V 5'-GACCACGCGTATCGATGTCGACTTTTTTTTTTTTTTTTV-3' plus Rv-1 5'-AACTAA TTCGTCGCTGCTCATA-3' and Fw-d(T)16V 5'-GACCACGCGTATCGATGTCGACTTTTTTTTTTTTTT TTV-3' plus Rv-2 5'-CTCAATTGCTGCCGCTGTG-3', respectively. The final PCR products were extracted from electrophoresis gel and used for Sanger sequencing with primer Rv-2.

Identification of genetic differences between phages with turbid and clear plaque morphotypes. In order to identify genetic differences between the Sam 46 types forming turbid and clear plaques (Sam46-T and Sam46-C, respectively), separate plaques with different morphology were used for T-type and C-type phage extraction followed by obtaining high-titer phage samples, phage DNA extraction and whole genome sequencing (WGS) as mentioned above.

To obtain mutant phages Sam46-C and Sam112-C from Sam46-T and Sam112-T, respectively, T-type phages were propagated in $30 \mathrm{ml}$ of $\mathrm{LB}$ broth $\left(10 \mathrm{mM} \mathrm{CaCl}_{2}, 10 \mathrm{mM} \mathrm{MgCl}_{2}\right)$ inoculated with $300 \mu \mathrm{l}$ of $B$. cereus VKM B-370 culture (OD590 0.6). Cultivation was continued at $37^{\circ} \mathrm{C}$ until optical density decreased. The cell debris was removed by centrifugation at $12,000 \mathrm{~g}$ for $10 \mathrm{~min}$ at $4{ }^{\circ} \mathrm{C}$. Phage particles were precipitated from the obtained lysates with PEG 8,000 as described previously ${ }^{29}$. The propagation-precipitation cycles were repeated three times. Then, $10 \mu \mathrm{l}$ of the final concentrated T-type phage suspensions diluted to $10^{4}$ plaque-forming units (PFU)/ml were mixed with $100 \mu \mathrm{l}$ of $B$. cereus VKM B-370 culture (OD590 0.6) and $5 \mathrm{ml}$ of LB top agar (0.75\%) and overlaid on LB agar plates (1.5\% w/v agar) in Petri dishes. Incubation was performed at $37^{\circ} \mathrm{C}$ overnight for the formation of phage plaques and detection of turbid-to-clear plague mutations. Thus, 40 plates were analyzed for each T-type phage (Sam46-T and Sam112-T). For each phage, three clear plaques were selected for further manipulations. The selected mutated plaques were separately transferred into $50 \mu \mathrm{l}$ of Milli-Q water and incubated for $15 \mathrm{~min}$ at $95^{\circ} \mathrm{C}$. Two microliters of each mixture were used as PCR templates. PCRs were carried out consecutively using the TaqSE DNA polymerase (SibEnzyme, Cat. \# E314) and the pair of oligonucleotides: Sam46-112_CDS_24_Fw 5'-TCTATTTTCAAAGCAAGCGG-3' and Sam46-112_CDS_26_Rv 5'-GCTAATTTCTTAACCGGTTC-3'. PCR products were extracted from electrophoresis gel and used for Sanger sequencing with the primer Sam46112_CDS_24_Fw 5'-TCTATTTTCAAAGCAAGCGG-3'.

The phage mutants with turbid plaques from Sam46-C and Sam112-C were obtained similarly.

Prediction of protein secondary structures. Secondary structure prediction of the gp 25 gene products of Sam 46 and Sam 112 phages was performed with JPRED4 incorporating the Jnet algorithm v2.3.1 ${ }^{49}$. The oligomeric state probabilities of a coiled-coil sequence were predicted by LOGICOIL algorithm ${ }^{50}$.

Thermal and pH stability of the Sam46-T and Sam46-C phages. In order to assess the stability of Sam46-T and Sam46-C phages at various temperatures, aliquots of phage suspensions at a titer of $5 \times 10^{8}$ plaque-forming units (PFU)/ml were incubated at 4, 30, 40, 50, 60, 70, 80, $90^{\circ} \mathrm{C}$ for $1 \mathrm{~h}$. In addition, phage stability at $\mathrm{pH}$ values ranging from 2.2 to 10 was determined using three different buffers: $\mathrm{SM}+\mathrm{buffer}$ ( $\mathrm{pH}$ values 6-10), sodium acetate buffer ( $\mathrm{pH} 4$ and 5), and Glycine- $\mathrm{HCl}$ buffer ( $\mathrm{pH} 2.2$ and 3). The Sam46-T and Sam46-C phages were added to each $\mathrm{pH}$ solution to the final concentration of $5 \times 10^{8}$ and incubated for $1 \mathrm{~h}$ at $37^{\circ} \mathrm{C}$. The surviving phages from both thermal and $\mathrm{pH}$ stability experiments were enumerated by double-layer plate titration. The experiment was performed with three replicates. The results were visualized in SigmaPlot v.12.5 as the mean of three observations \pm standard deviation. 
Killing assay. To assess the killing activity of the Sam46-C and Sam46-T phages, the B. cereus VKM B-370 strain was separately infected with the Sam 46-C and Sam46-T phages at different multiplicity of infection (MOI) values. Briefly, $50 \mu \mathrm{l}$ of phage suspensions $\left(2 \times 10^{9}, 2 \times 10^{8}\right.$ and $\left.2 \times 10^{7} \mathrm{PFU} / \mathrm{ml}\right)$ were mixed separately in a 48-well microplate with $450 \mu \mathrm{l}$ of mid- $\log B$. cereus VKM B-370 culture at a concentration of $2 \times 10^{7}$ colonyforming units $(\mathrm{CFU}) / \mathrm{ml}$ to provide $\mathrm{MOI}$ values of 10,1 , and 0.1 , respectively. The microplate was incubated with shaking for $7 \mathrm{~h}$ at $30^{\circ} \mathrm{C}$ in a FilterMax F5 microplate reader (Molecular Devices), with OD595 being measured every $10 \mathrm{~min}$. Non-infected B. cereus VKM B-370 culture was used as a control sample. The experiment was performed with three replicates. The results were reported as the mean of three observations \pm standard deviation. The obtained growth curves were visualized in SigmaPlot v.12.5.

Adsorption assay. To determine the time required for the Sam46-T and Sam46-C phages to attach to $B$. cereus VKM B-370 cells, an adsorption assay was performed according to the protocol developed by Kropinski ${ }^{51}$. Briefly, $0.95 \mathrm{ml}$ of LB broth with three drops of chloroform were added to Eppendorf tubes and placed on ice to chill for 10 min. Mid-log phase B. cereus VKM B-370 culture (OD590 0.4) grown in LB broth with the addition of $10 \mathrm{mM} \mathrm{CaCl}_{2}$ and $10 \mathrm{mM} \mathrm{MgCl}_{2}$ was diluted to OD590 of 0.2 . Nine milliliters of the culture were transferred to a $100-\mathrm{ml}$ laboratory flask and the flask was placed into a shaking water bath at $37^{\circ} \mathrm{C}, 60 \mathrm{rpm}$. Nine milliliters of $\mathrm{LB}$ broth with $10 \mathrm{mM} \mathrm{CaCl}_{2}$ and $10 \mathrm{mM} \mathrm{MgCl}_{2}$ were used as a control sample. Immediately, $1 \mathrm{ml}$ of the Sam 46-T or Sam 46-C phage suspension at a concentration of $2 \times 10^{5} \mathrm{PFU} / \mathrm{ml}$ (preheated for $5 \mathrm{~min}$ at $37^{\circ} \mathrm{C}$ ) was added to both tested and control flasks. Every $5 \mathrm{~min}, 50-\mu$ laliquots were collected from both tested and control flasks, transferred into the prepared Eppendorf tubes containing LB and chloroform, and mixed vigorously in a vortex mixer. The mixtures were assayed for unadsorbed phages by double-layer plate titration, and the resulting phage titers were compared to those obtained for the control samples (without host cells). This experiment was performed three times for each phage (Sam46-T and Sam46-C). The results were presented as percentages of the initial phage number and visualized in SigmaPlot v.12.5 with error bars representing standard deviation for three replicates. The adsorption rate was calculated using the equation described by Kropinski ${ }^{51}$.

One-step growth curve. In order to determine the latent period and the average burst size of the Sam46-T and Sam46-C phages, the one-step growth experiment was performed as described by Hyman and Abedon ${ }^{52}$. Briefly, $1 \mathrm{ml}$ of phage suspension (preheated for $5 \mathrm{~min}$ at $37^{\circ} \mathrm{C}$ ) at a concentration of $2 \times 10^{7}$ was mixed with 9 $\mathrm{ml}$ of the B. cereus VKM B-370 culture grown to the mid-log phase (OD590 0.4) and diluted to OD590 of 0.2 to provide MOI of 0.1 . After the incubation at $37^{\circ} \mathrm{C}$ for $10 \mathrm{~min}$ for phage adsorption, a 1-ml aliquot was collected and centrifuged at $3,500 \mathrm{~g}$ for $10 \mathrm{~min}$ at $4{ }^{\circ} \mathrm{C}$ to precipitate the cells. The supernatant was removed and the pellet was resuspended in $1 \mathrm{ml}$ of fresh LB broth, centrifuged and resuspended in $1 \mathrm{ml}$ of LB again. $0.1 \mathrm{ml}$ of the mixture (bacteria with adsorbed phages) was transferred to $9.9 \mathrm{ml}$ of LB growth medium in a 100-ml flask, mixed thoroughly and placed in a shaking water bath $(60 \mathrm{rpm})$ at $37^{\circ} \mathrm{C}$. Aliquots of $150 \mu \mathrm{l}$ of the mixture were collected at 5-min intervals for $1 \mathrm{~h}$. The phages were enumerated by double-layer plate titration at each time point, including time point 0 . The experiment was performed in triplicate for each phage (Sam46-T and Sam46C). The PFU/ml values were calculated and plotted against time. The latent period and phage burst size were calculated from the plotted curve visualized in SigmaPlot v.12.5 with error bars representing standard deviation for three replicates.

Phage immunity test. The potentially phage-immune cells of $B$. cereus VKM B-370 were collected from the central part of five turbid plaques formed by the Sam46-T phage and then plated onto LB agar plates by the streak plate method and incubated overnight at $37^{\circ} \mathrm{C}$. Single colonies were transferred into liquid LB medium and grown overnight at $37^{\circ} \mathrm{C}$ with shaking. Next, $30 \mu \mathrm{l}$ of the overnight bacterial cultures were transferred into $3 \mathrm{ml}$ of fresh LB medium and incubated with shaking at $37^{\circ} \mathrm{C}$ until OD590 reached $0.4-0.45$. The mid-log phase bacterial cultures were diluted to the OD590 of 0.2. Fifty microliters of the Sam46-T and Sam46-C phages at the concentrations of $6 \times 10^{7} \mathrm{PFU} / \mathrm{ml}$ were added separately into a 48 -well microplate to $450 \mu \mathrm{l}$ of diluted bacterial cultures to provide MOI of about 2. The microplate was incubated for $7 \mathrm{~h}$ at $30^{\circ} \mathrm{C}$ in the FilterMax F5 microplate reader (Molecular Devices), with OD595 being measured every $10 \mathrm{~min}$. Non-infected cultures were used as control samples. Optical density was measured three times for both original B. cereus VKM B-370 cells and the potentially phage-immune $B$. cereus VKM B-370 cells. The obtained growth curves were visualized in SigmaPlot 12.5 with error bars representing standard deviation for three replicates.

Accession number. The genome sequences and associated data for phages Sam 46 and Sam112 were deposited under GenBank accession number MN604698.1 and MN604230.1, BioProject accession numbers PRJNA686639 and PRJNA686641, BioSample accession numbers SAMN17119830 and SAMN17119843, SRA accession numbers SRR13276100 and SRR13276285, respectively. Associated data for the T-type and C-type Sam46 phage genomes were submitted under BioProject accession number PRJNA686639, BioSample accession numbers SAMN17119841 and SAMN17119842, SRA accession numbers SRR13276014 and SRR13276013, respectively.

\section{Results}

Isolation, host range and morphology. Bacillus phages Sam46 and Sam112 were isolated from soil samples collected in Samara, Russian Federation. Both Sam46 and Sam112 produced clear and turbid plaques, approximately $1 \mathrm{~mm}$ in diameter, on the lawn of the host strain VKM B-370 (Supplementary Information, Fig. S1 and Fig. S2). Purified phage suspensions of both Sam46 and Sam112 that stably produced only one type 


\begin{tabular}{|c|c|c|c|c|c|c|c|c|}
\hline No. & Species & Strain & $\begin{array}{l}\text { Sam46 } \\
\left(O^{*}\right)\end{array}$ & $\begin{array}{l}\text { Sam46 } \\
\left(C^{* *}\right)\end{array}$ & $\begin{array}{l}\text { Sam46 } \\
\left(T^{* * *}\right)\end{array}$ & $\begin{array}{l}\text { Sam112 } \\
\left(O^{*}\right)\end{array}$ & $\begin{array}{l}\text { Sam112 } \\
\left(C^{* *}\right)\end{array}$ & $\begin{array}{l}\text { Sam112 } \\
\left(T^{* * *}\right)\end{array}$ \\
\hline 1 & B. cereus & VKM B-13 & + & + & + & + & + & + \\
\hline 2 & B. cereus & VKM B-15 & - & - & - & - & - & - \\
\hline 3 & B. cereus & VKM B-370 & + & + & + & + & + & + \\
\hline 4 & B. cereus & VKM B-373 & + & + & + & + & + & + \\
\hline 5 & B. cereus & VKM B-383 & + & + & + & + & + & + \\
\hline 6 & B. cereus & VKM B-445 & - & - & - & - & - & - \\
\hline 7 & B. cereus & VKM B-473 & + & + & + & + & + & + \\
\hline 8 & B. cereus & VKM B-491 & + & + & + & + & + & + \\
\hline 9 & B. cereus & VKM B-504 ${ }^{\mathrm{T}}$ & - & - & - & - & - & - \\
\hline 10 & B. cereus & VKM B-682 & - & - & - & - & - & - \\
\hline 11 & B. cereus & VKM B-683 & + & + & + & + & + & + \\
\hline 12 & B. cereus & VKM B-684 & + & + & + & - & - & - \\
\hline 13 & B. cereus & VKM B-686 & + & + & + & + & + & + \\
\hline 14 & B. cereus & VKM B-688 & + & + & + & + & + & + \\
\hline 15 & B. cereus & VKM B-771 & - & - & - & - & - & - \\
\hline 16 & B. cereus & VKM B-810 & - & - & - & - & - & - \\
\hline 17 & B. cereus & VKM B-812 & - & - & - & - & - & - \\
\hline 18 & B. cereus & VKM B-861 & + & + & + & + & + & + \\
\hline 19 & B. cereus & ATCC 4342 & - & - & - & - & - & - \\
\hline 20 & B. cereus & ATCC 14893 & - & - & - & - & - & - \\
\hline 21 & B. thuringiensis & VKM B-83 & - & - & - & - & - & - \\
\hline 22 & B. thuringiensis & VKM B-84 & - & - & - & - & - & - \\
\hline 23 & B. thuringiensis & VKM B-440 & + & + & + & + & + & + \\
\hline 24 & B. thuringiensis & VKM B-443 & - & - & - & - & - & - \\
\hline 25 & B. thuringiensis & VKM B-446 & + & + & + & + & + & + \\
\hline 26 & B. thuringiensis & VKM B-447 & - & - & - & - & - & - \\
\hline 27 & B. thuringiensis & VKM B-450 & + & + & + & + & + & + \\
\hline 28 & B. thuringiensis & VKM B-454 & + & + & + & + & + & + \\
\hline 29 & B. thuringiensis & VKM B-1555 & + & + & + & + & + & + \\
\hline 30 & B. thuringiensis & VKM B-1557 & + & + & + & + & + & + \\
\hline 31 & B. thuringiensis & ATCC 35646 & - & - & - & - & - & - \\
\hline 32 & B. weihenstephanensis & KBAB4 & - & - & - & - & - & - \\
\hline
\end{tabular}

Table 1. The host range of Bacillus phages Sam 46 and Sam112 for 32 Bacillus strains. $\mathrm{O}^{*}$, original phage suspension producing two types of plaques: clear and turbid; $\mathrm{C}^{\star *}$ and $\mathrm{T}^{\star * *}$, purified phage suspensions producing only one type of plaques: clear plaques or turbid plaques, respectively.

of plaques were obtained after five cycles of the extraction-titration procedure. Thus, four phages were ultimately obtained: Sam46-C, Sam46-T, Sam112-C and Sam112-T. The letters C and T indicate the morphotypes of plaques formed by the phages: clear and turbid morphotype, respectively. A host range test was carried out for 32 strains of the B. cereus group. Both original and purified (producing uniform plaques) suspensions of Sam 46 and Sam 112 were capable of forming plaques on the lawns of 17 and 16 (out of 32 ) strains $(\sim 50 \%)$, respectively (Table 1).

The TEM analysis revealed that both Sam 46 and Sam 112 (for each phage, $\mathrm{n}=10$ phage particles) possess an icosahedral non-elongated head of approximately $57.62 \pm 1.2 \mathrm{~nm}$ in diameter attached to a characteristic long contractile nonflexible tail of approximately $160.0 \pm 5.5 \mathrm{~nm}$ in length (including the baseplate structure) and $16.9 \pm 1.3 \mathrm{~nm}$ in width, ending with a baseplate structure with six tail fibers. These phages have the characteristic morphological features of the myovirus morphotype (Fig. 1).

General genome organization of Sam46 and Sam112. The Sam46 genomic sequence contains 45,419 bp with the GC-content of $41.6 \%$ and 77 predicted ORFs. The Sam 112 genome is slightly shorter, with 45,037 bp, 75 predicted ORFs and the same GC-content. According to the BLASTn (NCBI), these phages have the whole genome identity value of $96.0 \%$ (Supplementary Information, Table S3), indicating that they belong to the same phage species in accordance with the official ICTV classification, as the currently used species demarcation criterion is the genome nucleotide identity of $95 \%{ }^{53,54}$. The circular genome map of Sam 46 is shown in Fig. 2, with the first base of small terminase subunit gene selected as the starting point of the genome.

The putative functions were assigned to 44 (57.1\%) and 44 (58.7\%) ORFs of Sam46 and Sam112, respectively, using BLASTp (NCBI) ${ }^{33}$ and HHpred ${ }^{34}$. More detailed information about the predicted ORFs is provided in Tables S1 and S2 (Supplementary Information, Table S1, Table S2). 
a

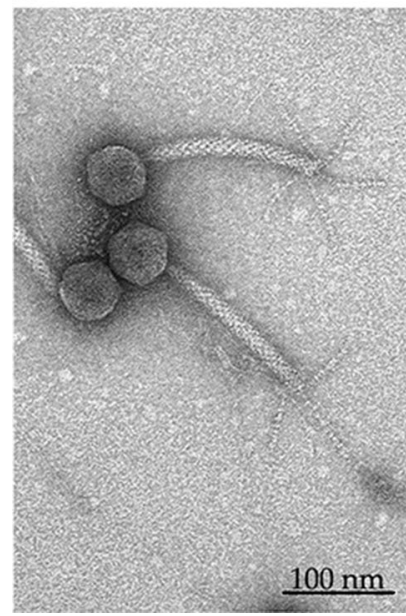

b

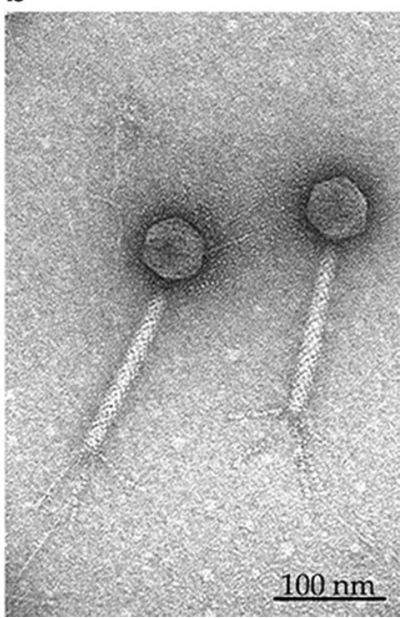

Figure 1. Transmission electron microscopy of Bacillus phages (a) Sam46 and (b) Sam112 negatively stained with $1 \%(w / v)$ uranyl acetate. Scale bar $100 \mathrm{~nm}$. The full-length TEM micrographs of Sam46 and Sam112 are presented in Supplementary Figures S3 and S4, respectively.

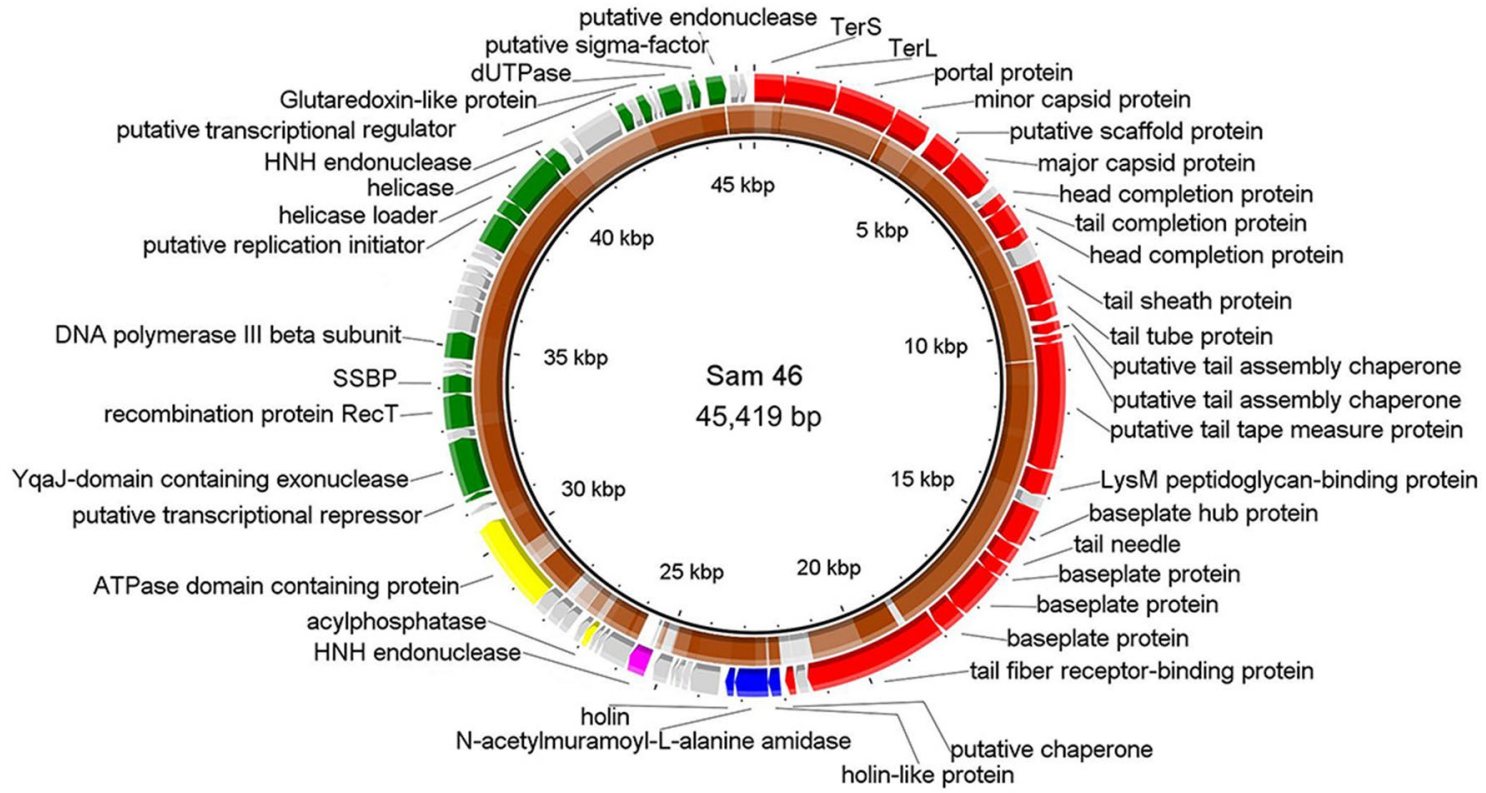

holin-like protein

DNA packaging and structural proteins

DNA metabolism, replication, recombination

Host cell lysis

\section{Sam 112}

Other function

Unknown function
$100 \%$ identity

$90 \%$ identity

$80 \%$ identity

Figure 2. The Sam46 genome map visualized with BRIG software v.0.95 (http://brig.sourceforge.net). The inner ring shows the level of Sam 112 genomic identity (tBLASTx e-value significance) to Sam46, from unrelated (white regions) to closely related (dark brown), according to the legend. Fuchsia arrow in Sam46 genome indicates the HNH-endonuclease absent in Sam112.

DNA packaging genes. In the case of both phages Sam46 and Sam112, ORF1 (locus_tag: Sam46_gp1, Sam112_ gp1) and ORF2 (locus_tag: Sam46_gp2, Sam112_gp2) encode the small and large terminase subunit, respectively. ORF1s have been found to possess a two-domain structure: C-terminal Terminase_2 domain (residues 107-230) (E-value $1.2 e^{-27}$ ), the typical domain of phage small terminase subunits, and N-terminal FtsK_gamma domain (residues 11-70) (E-value $\sim 2 e^{-27}$ ), which is occasionally encoded in a separate ORF in some phages but not in such a fusion. The role of single FtsK_gamma-like genes in phage genomes is still unknown. The 
a

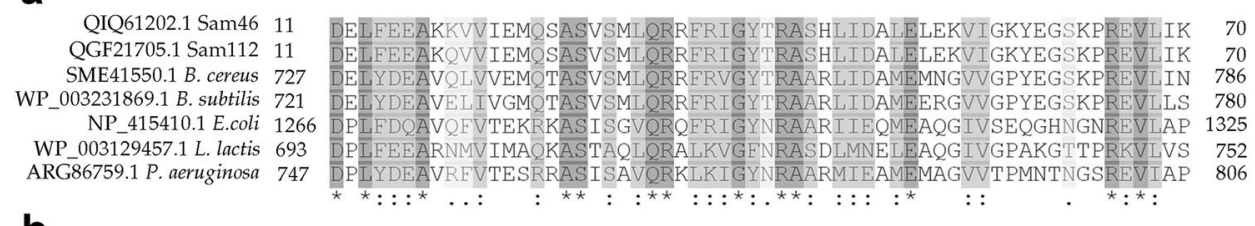

b

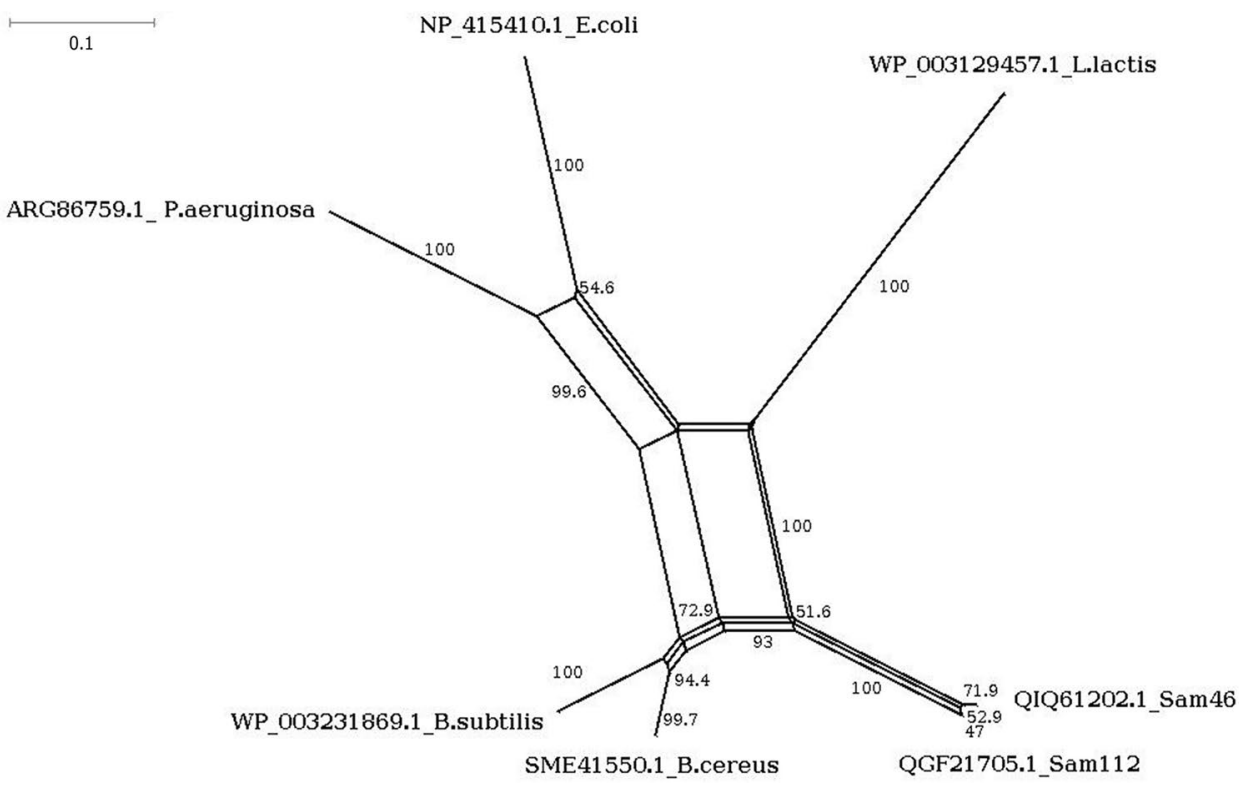

Figure 3. The sequence analysis of FtsK-like protein gamma domain. (a) Sequence alignment of the FtsK-like protein gamma domain by MAFFT version 7 (https://mafft.cbrc.jp/alignment/server). Accession numbers and species name are labeled on the left side of each alignment. Numbers located on both sides of the alignments indicate the exact positions of each sequence. (b) Neighbor-Net network tree of FtsK_gamma domains by SplitTree4 v.4.16.1 (https://software-ab.informatik.uni-tuebingen.de/download/splitstree/welcome.html). Accession number and species name are labeled at the ends of the branches. Numbers on the branches indicate bootstrap test values with 1000 replicates. Scale bar: number of substitutions per site.

FtsK_gamma domain is a winged helix subdomain of the C-terminal DNA translocation motor component of FtsK and SpoIIIE proteins, coordinating the proper segregation of bacterial chromosomes during cell division and sporulation, respectively ${ }^{55,56}$. The bacterial FtsK_gamma domain acts as a DNA-binding domain that recognizes and binds the specific chromosomal sequences of $8 \mathrm{bp}$ in length, known as KOPS (FtsK Orienting Polarized Sequences) 55,57,58 or FRS (FtsK Recognition Sequence), and in the case of SpoIIIE known as SRS (SpoIIIE Recognition Sequence) $)^{59}$.

The alignment of the FtsK_gamma domains of Sam 46 and Sam112 small terminase subunits with the bacterial FtsK_gamma domains (B. cereus, B. subtilis, E. coli, L. lactis and P. aeruginosa) (Fig. 3a) has revealed that the DNA binding sites of FtsK_gamma domains of both phages are highly conserved among bacteria. The phylogenetic analysis of FtsK_gamma domains indicated that those from B. cereus and B. subtilis are most closely related to the FtsK_gamma domains of Sam 46 and Sam112 (Fig. 3b). Therefore, the FtsK_gamma domains of the small terminase subunits of Sam 46 and Sam 112 were probably acquired from bacterial hosts during co-evolution.

Searching Sam 46 and Sam 112 genomes for bacterial KOPS/SRS such as B. subtilis: $5^{\prime}$-GAGAAGGG-3 ${ }^{\prime 59}$; E. coli: $5^{\prime}$-GGGNAGGG-3 ${ }^{\prime 57}$,L. lactis: $5^{\prime}-$ GAGAAG- $3^{\prime 58}$ and $P$. aeruginosa $5^{\prime}$-GGGCAGGG- $3^{\prime 60}$ sequences has revealed the presence of only two E. coli KOPS and 15 L. lactis KOPS for both phages.

Atypical domain structure of the small terminase subunits of phages Sam46 and Sam 112 indicates that the Sam46 and Sam112 genomes might contain KOPS/SRS-like binding sites for the small terminase.

Morphogenesis and lytic genes. The morphogenesis genes of Sam 46 and Sam 112 were identified using BLAST and HHpred, taking into account the predicted structural similarities with the known orthologous proteins. The capsid genes with the predicted functions include SPP1 Gp6-like portal protein (Sam46_gp3, Sam112_gp3), minor capsid protein (Sam46_gp4; Sam112_gp4), putative scaffold protein (Sam46_gp5, Sam112_gp5), SPP1 Gp13-like major capsid protein (Sam46_gp6, Sam112_gp6), SPP1 Gp15-like head completion protein (Sam46_ gp8, Sam112_gp8) and XkdH-like head completion protein (Sam46_gp10, Sam112_gp10). Functionally assigned tail genes include tail completion protein (Sam46_gp9, Sam112_gp9), tail sheath protein (Sam46_gp12, Sam112_gp12), tail tube protein (Sam46_gp13; Sam112_gp13), putative tail tape measure protein (Sam46_gp16; 


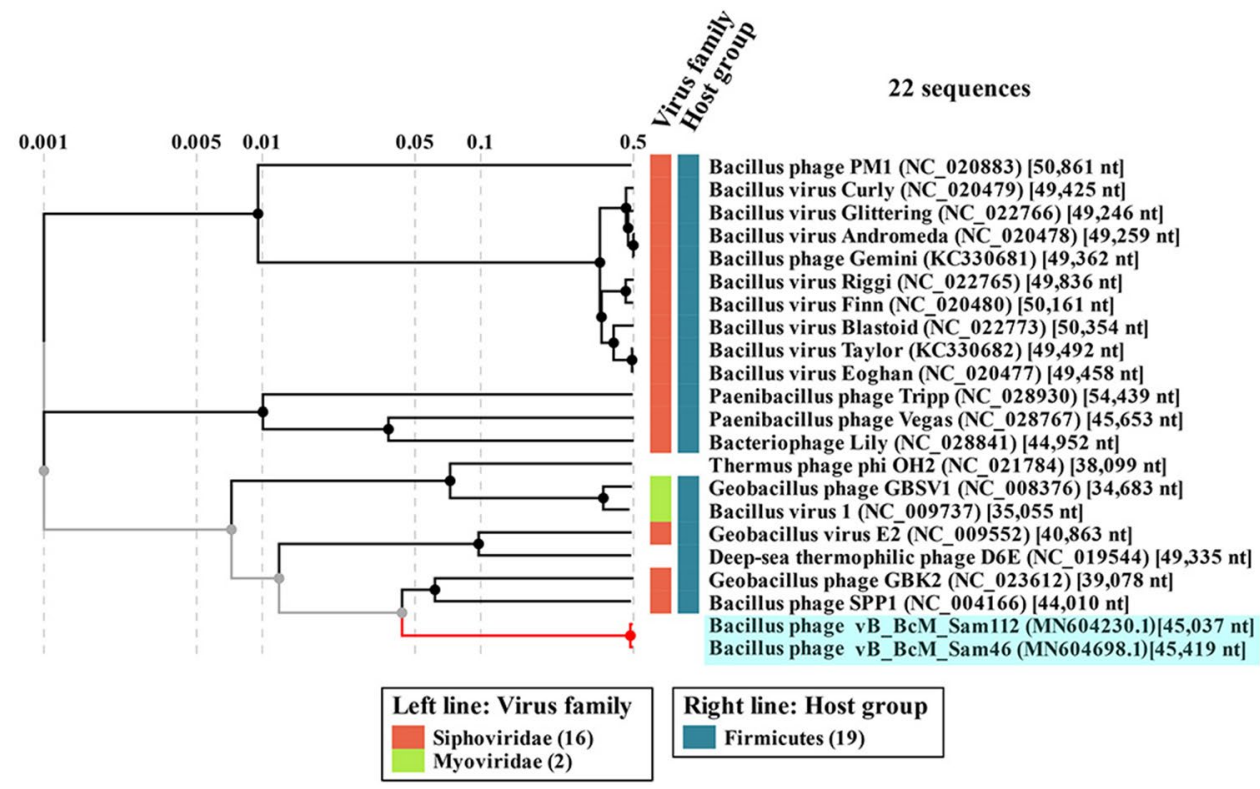

Figure 4. Phylogenetic relationship of Sam 46 and Sam 112 to the known phages. The tree was generated using the ViPTree server version 1.9 (https://www.genome.jp/viptree/) based on genome-wide sequence similarities computed by tBLASTx. The clade containing the members of of the proposed new genus 'Samaravirus' is highlighted in light blue.

Sam112_gp16), LysM domain-containing peptidoglycan-binding protein (Sam46_gp17, Sam112_gp17), baseplate hub protein (Sam46_gp19, Sam112_gp19), tail needle (Sam46_gp20, Sam112_gp20), three baseplate proteins (Sam46_gp21, Sam112_gp21; Sam46_gp22, Sam112_gp22; Sam46_gp23, Sam112_gp23, respectively) with predicted structural homology to Gp25 T4, GpJ and GpI P2, tail fiber receptor-binding protein (Sam46_ gp24, Sam112_gp24) and three putative tail assembly chaperones (Sam46_gp14, Sam112_gp14; Sam46_gp15, Sam112_gp15; Sam46_gp16, Sam112_gp16, respectively).

Although Sam46 and Sam112 share several structural genes with bacteriophage SPP1, a member of the Siphoviridae family, their structural gene modules are much more similar to that of the deep-sea thermophilic phage D6E (Fig. 6), a myovirus with a highly mosaic genome ${ }^{61}$.

Replication and recombination genes. The module of replication- and recombination-related genes of Sam 46 resembles that of the virulent Bacillus bacteriophage SPP1 (Fig. 2) and belongs to the "initiator-helicase-helicase loader" type according to the classification proposed by Weigel and Seitz ${ }^{62}$. It includes the adjacently encoded DnaD domain-containing putative replication initiator (Sam46_gp61; Sam112_gp58), lambda P-related helicase loader (Sam46_gp62; Sam112_gp59) and DnaB-type replicative helicase (Sam46_gp63; Sam112_gp60). Sam46_gp47 (Sam112_gp60) and Sam46_gp49 (Sam112_gp47) encode products with apparent homology to YqaJ domain-containing exonuclease and RecT-like protein, respectively, which thereby seem to be parts of the two-component recombination system functionally similar to SPP1 Gp34.163 and Gp35 ${ }^{64}$. Sam46_gp46 (Sam112_gp48) is an E. coli-type single stranded DNA binding (SSB) protein known to be frequently associated with such a recombination system ${ }^{62,65}$. Sam46_gp53 (Sam112_gp50) is the processivity factor (DNA sliding clamp) of PolIII $\beta$-type, which is most abundant among bacteriophages ${ }^{62}$.

Comparative genomics. To assess the phylogenetic relationship of the Sam46 and Sam112 to known phages, ViPTree server version 1.9 was used to generate a proteomic tree based on the genome-wide sequence similarities computed by tBLASTx (Fig. 4). As can be seen in Figure 4, Sam46 and Sam112 form a separate branch significantly distant from the closest relatives. The most closely related genomes belong to bacteriophages SPP1 and GBK2, which are both siphoviruses.

In addition, the number of shared proteins was computed using the GET_HOMOLOGUES software (Supplementary Information, Table S4), and a pangenome matrix was produced showing the presence/absence of representatives of individual gene/protein clusters in each genome. Based on the matrix, a Maximum-likelihood (ML) tree was drawn (Fig. 5), where the intergenomic distances are computed from the number of shared proteins. According to Table S3 and Fig. 5, the myovirus D6E shares slightly more proteins (20) than SPP1 (16) with Sam46. Thus, the VipTree and GET_PHYLOMARKERS phylogenetic analyses failed to give consistent results, which is not in any way surprising: both SPP1 and D6E share less than 23\% of their proteins with Sam 46 , therefore, for the question which one of them is the closest relative to make sense, both are far too distant.

The linear whole genome comparison diagram was also visualized with the ViPTree server version 1.9 (Fig. 6), showing tBLASTx pairwise similarities between the most closely related genomes. As illustrated on the diagram, both the SPP1 and D6E genomes contain regions of local similarity to the Sam 46 and Sam 112 genomes, although 


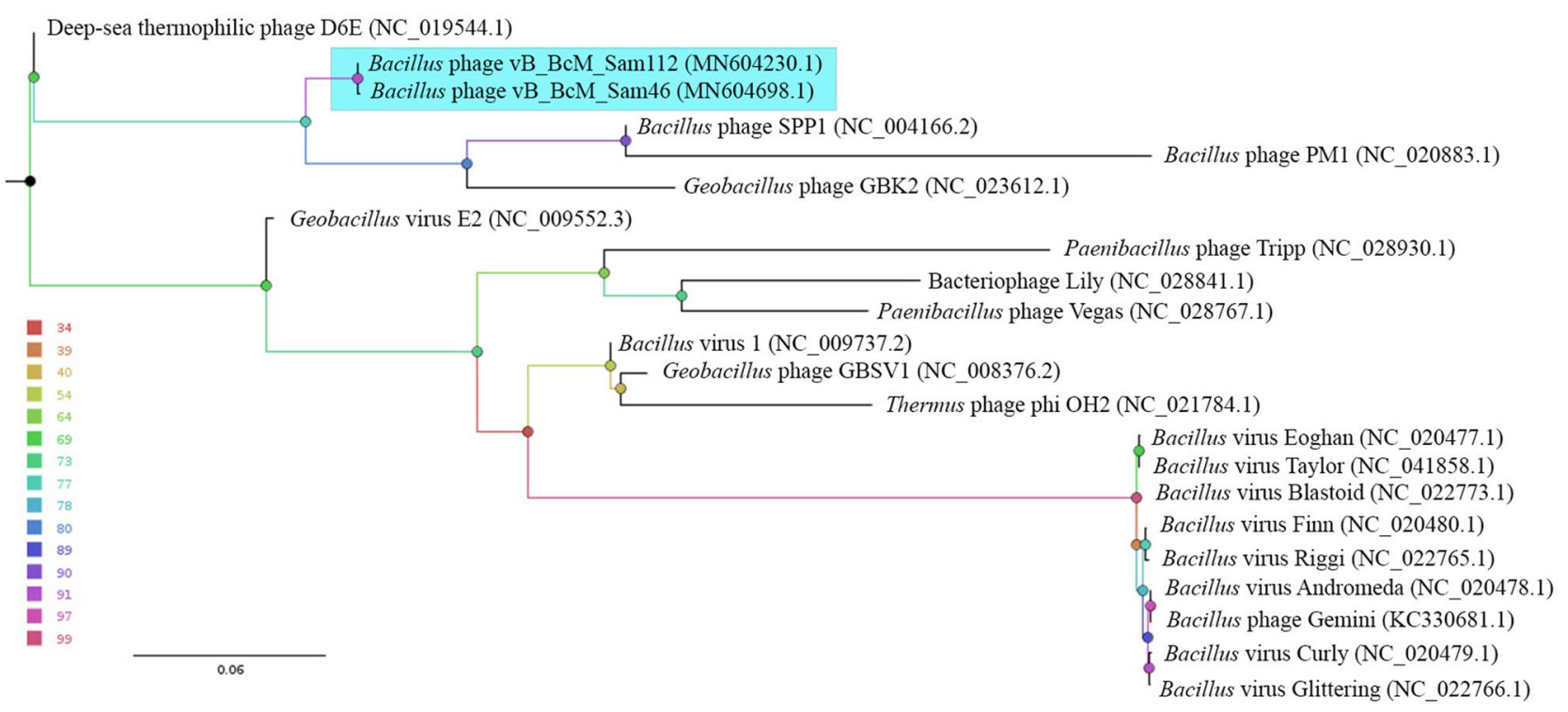

Figure 5. The Maximum-likelihood pan-genome tree for Sam46, Sam 112 and the closest viruses inferred from the presence/absence pangenome matrix using GET_PHYLOMARKERS software package version 2.2.8.1 (http://github.com/vinuesa/get_phylomarkers) and visualized with FigTree v1.4.4 (http://tree.bio.ed.ac.uk/softw are/figtree/). The nodes are colored according to the legend, which represents standard bootstrap support values. The clade containing the members of the proposed new genus 'Samaravirus' is highlighted in blue.

within different gene modules. D6E shares many structural genes with Sam112, whereas the similarity between SPP1 and Sam 46 is mostly limited to replication-related genes. This indicates that different parts of the Sam 46 and Sam 112 genomes were acquired from different sources and that phages that are more closely related to Sam 46 and Sam 112 are still to be discovered. The discovery of such phages would allow us to reconstruct the history of the biggest recombination events that have led to the observed mosaicity of the Sam 46 and Sam 112 genomes.

Determination of packaging strategy. In the case of both Sam46 and Sam112, relatively homogeneous coverage with no significant peaks (with double or more than double depth of coverage) was observed on the coverage plot by the Bowtie2 software tool v.2.3.4.3 (Fig. 7a), which is typical of phages with circularly permuted terminal repeats using the headful mechanism of DNA packaging ${ }^{37}$. The DNA packaging mode of Sam 46 and Sam 112 was experimentally confirmed by restriction analysis of the genomic DNA using restriction endonucleases HindIII, XbaI and HindIII with XbaI simultaneously. For both Sam46 and Sam112, on each track of the electrophoregrams we could find all of the fragments predicted in silico from artificially circularized genomic sequences and also an additional unexpected fragment appearing in submolar concentrations relative to others (Fig. 7b $)^{66}$. This type of restriction pattern is known to be characteristic of phages with the headful mode of DNA packaging ${ }^{66}$. The additional submolar fragments are so-called "pac-fragments", which are produced during the first packaging event at each genomic concatemer and, unlike true restriction fragments, are cut on one side by the phage terminase. The observed lengths of the pac-fragments allowed us to predict the approximate location of the pac-site, which is expected to be roughly $4.5 \mathrm{Kbp}$ upstream of the TerS gene in both Sam 46 and Sam 112 genomes.

The Sam 46 pac-fragments were extracted from the electrophoresis gel and used for determination of the pacsite location using the RAGE method followed by Sanger sequencing of the products obtained in the second PCR. For the HindIII- and XbaI-generated pac-fragments, the terminase-generated cut was found to be approximately at position 40,843 in the intergenic region upstream of Sam46_gp66, as is shown on the sequencing chromatograms (Fig. 7c). Thus, both Sam 46 and Sam112 apparently use the headful mechanism of DNA packaging with accurate site-specific initiation.

Identification of genetic differences between the phages with turbid and clear plaque morphotypes. DNA was extracted from the Sam46-T and Sam46-C phages as described in "Materials and methods". The whole genome sequencing of the Sam46-T and Sam46-C genomes showed differences in the genetic content of only one gene. The Sam46-T genome is completely identical to the originally sequenced Sam 46 genome, while the Sam46-C genome contains mutations in the gp25 gene (gene locus_tag: Sam46_gp25; protein ID: QIQ61226.1) encoding XkdW-like protein with unknown function (Fig. 8a).

The series of experiments on obtaining mutant phages with clear plaque morphotype Sam 46 and Sam 112 from Sam46-T and Sam112-T, respectively, followed by Sanger sequencing of the gp25 gene, confirmed the appearance of point mutations within this gene in C-type phages (Fig. 8a). The frequency of turbid-to-clear plaque mutations in both Sam46 and Sam112 was 1:3000.

All mutations identified in both WGS and the experiment on obtaining mutant C-type phages were found to be located strictly in the C-terminal region of the XkdW-like protein (Fig. 8a,b). Secondary structure prediction 


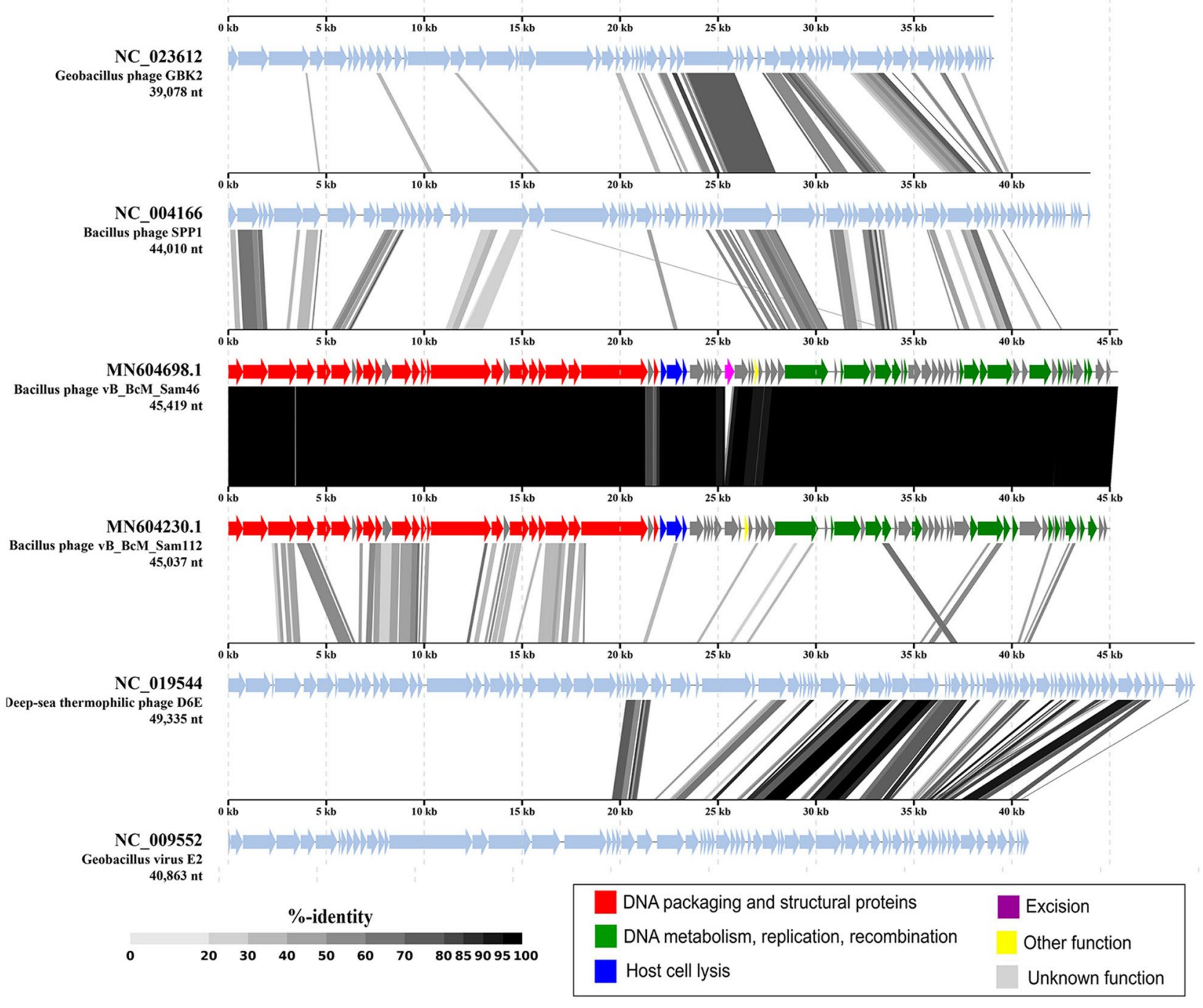

Figure 6. The tBLASTx comparison of the genomes of Sam46, Sam112 and the most related phages visualized with ViPTree server version 1.9 (https://www.genome.jp/viptree/). For Sam46 and Sam112, the color scheme corresponds to the supposed functions (the same as in Fig. 2). Fuchsia arrow in Sam46 genome indicates the HNH-endonuclease absent in Sam112.

by JPRED $4^{49}$ and coiled-coil region prediction by LOGICOIL ${ }^{50}$ have shown that the mutation region is an $\alpha$ -helix containing HPPHPPP patterns, referred to as heptad repeats (abcdfg) ${ }^{67}$, where hydrophobic residues $(\mathrm{H})$ generally occupy the "a" and "d" positions, and polar residues (P) occur on other positions (Fig. 8b,c). Such a structure of $\alpha$-helix is characteristic of the coiled-coil motif in proteins. According the LOGICOIL prediction ${ }^{50}$, the most probable state of coiled coils of XkdW-like proteins of both Sam 46 and Sam 112 is a parallel dimer.

The experiments on obtaining mutant phages with the turbid plaque morphotype from Sam46-C and Sam112$\mathrm{C}$ showed no results. Perhaps, the probability of the clear-to-turbid transition is extremely low.

Thermal and pH stability of the Sam46-T and Sam46-C phages. Taking into account the fact that the Sam 46 and Sam 112 phages are the same species according to the genome-wide analysis (the whole genome identity of $96.0 \%$ ), this and the subsequent experiments were performed only with Sam 46 as a representative of this species. In an attempt to explain the origin of two types of plaques, we performed the experiment for both Sam46-T and Sam46-C phages.

Both Sam46-T and Sam46-C phages were stable at temperatures of 30,40 and $50{ }^{\circ} \mathrm{C}$, as phage titers were similar to those of the control samples incubated at $4{ }^{\circ} \mathrm{C}$ (Fig. 9a,b). At $60^{\circ} \mathrm{C}$ or higher, the phage titer dropped sharply, no viral particles were detected after $1 \mathrm{~h}$ of incubation, and phage activity was completely lost (Fig. 9a,b). In addition, the results of $\mathrm{pH}$ stability tests showed that both Sam46-T and Sam46-C phages were stable at $\mathrm{pH}$ values from 5 to 10 (Fig. 9c,d). However, the Sam46-T and Sam46-C phages are not able to survive under highly acidic conditions, as no phages survived incubation in solutions at $\mathrm{pH} 2.2,3$ and 4 . 
a
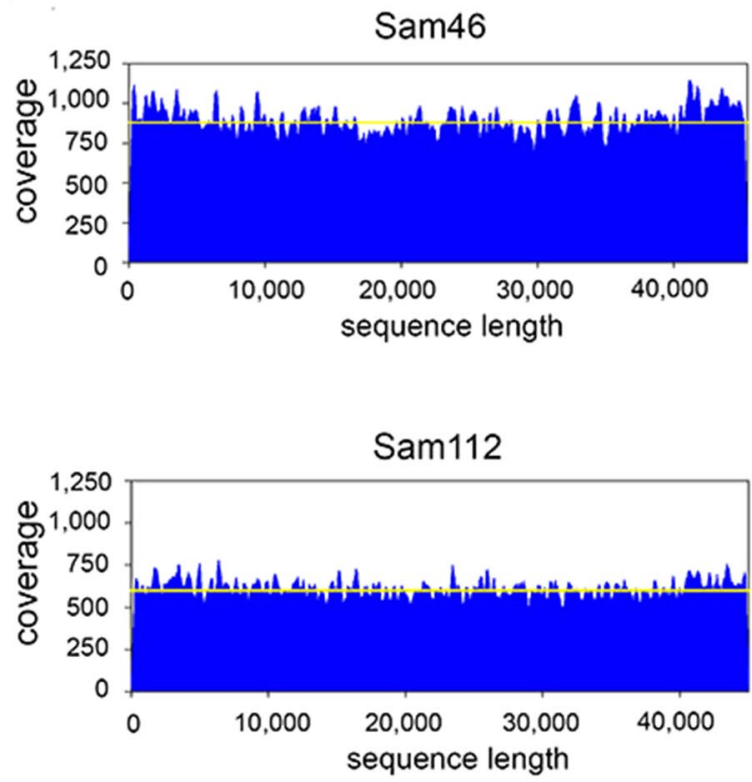

b

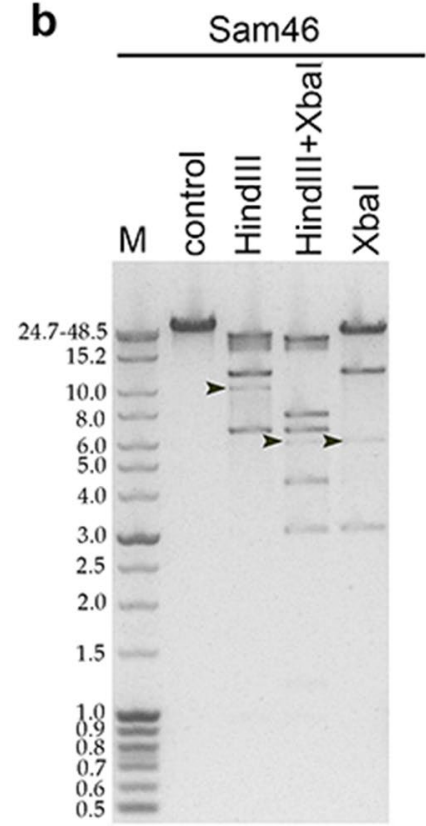

Sam112

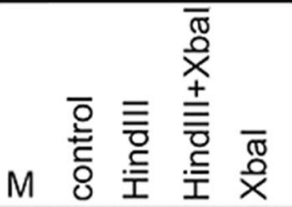

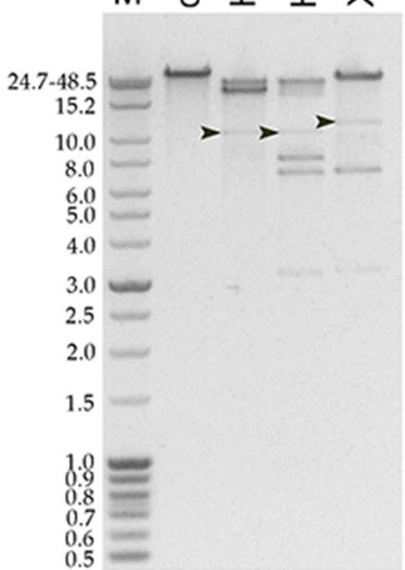

ORF\#66

C

AAAGGCAAGAGCAACGAGACAAAAGCGAACAAGTGCCCCGCGTACAGGAGGAAAAAGAA ATGATTCATTATCCGAATGGG

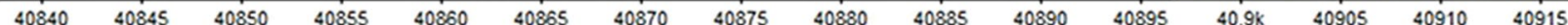
TTTCCGTTCTCGTTGCTCTGTTTTCGCTTGTTCACGGGGCGCATGTCCTCCTTTTTCTTTACTAAGTAATAGGCTTACCC terminase cutting for initiation

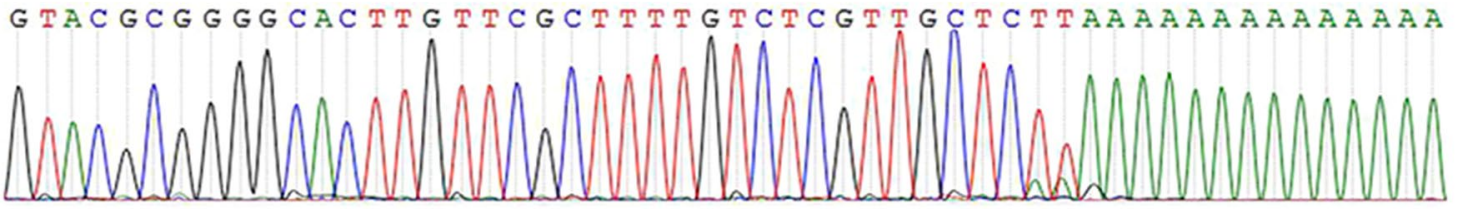

G TACGCGGGGCACT TG T T C G T T T T T T C T T G T T T TAAAAAAAAAAAA

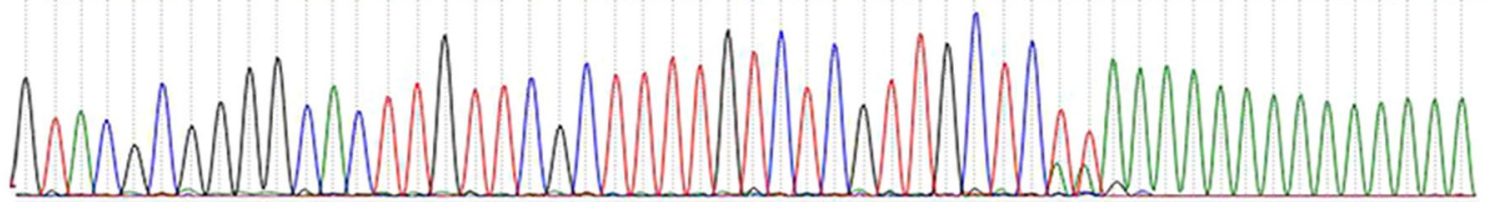

Xbal

Figure 7. Determination of packaging strategy. (a) Genome coverage plot was implemented with the Bowtie2 software tool v.2.3.4.3 (https://cpt.tamu.edu/galaxy-pub). No peaks deviate significantly from the mean (yellow line). (b) Restriction analysis of Sam46 and Sam112 DNA with enzymes XbaI and HindIII; M-molecular weight markers; black arrows indicate pac-fragments. The full-length gel is presented in Supplementary Figure S5. (c) Location of the terminase-generated cut in the Sam 46 genome. The terminal regions of the PCR product sequences obtained with RAGE for HindIII- and XbaI-generated pac-fragments are shown on the sequencing chromatograms.

Killing assay. Bacillus cereus VKM B-370 growth kinetics upon Sam46-C and Sam46-T infections at different MOI was studied by measuring OD595 of the cultures infected with C-type or T-type phages and comparing it to that of the non-infected control culture. The resultant bacterial growth curves are shown in Fig. 10. Both Sam46-T and Sam46-C infections resulted in the inhibition of bacterial growth, which became stronger as the MOI increased. However, the B. cereus VKM B-370 growth patterns upon Sam46-C and Sam46-T infections differ significantly at the MOI of 0.1 and 1 . The observed difference in the rates of host cell lysis, and, consequently, in the plaque morphotypes of Sam46-C and Sam46-T (Supplementary Information, Fig. S1) may have different explanations, the simplest one being the formation of lysogens. However, in the 'Phage immunity test' section below we show that it does not appear to be the case. 


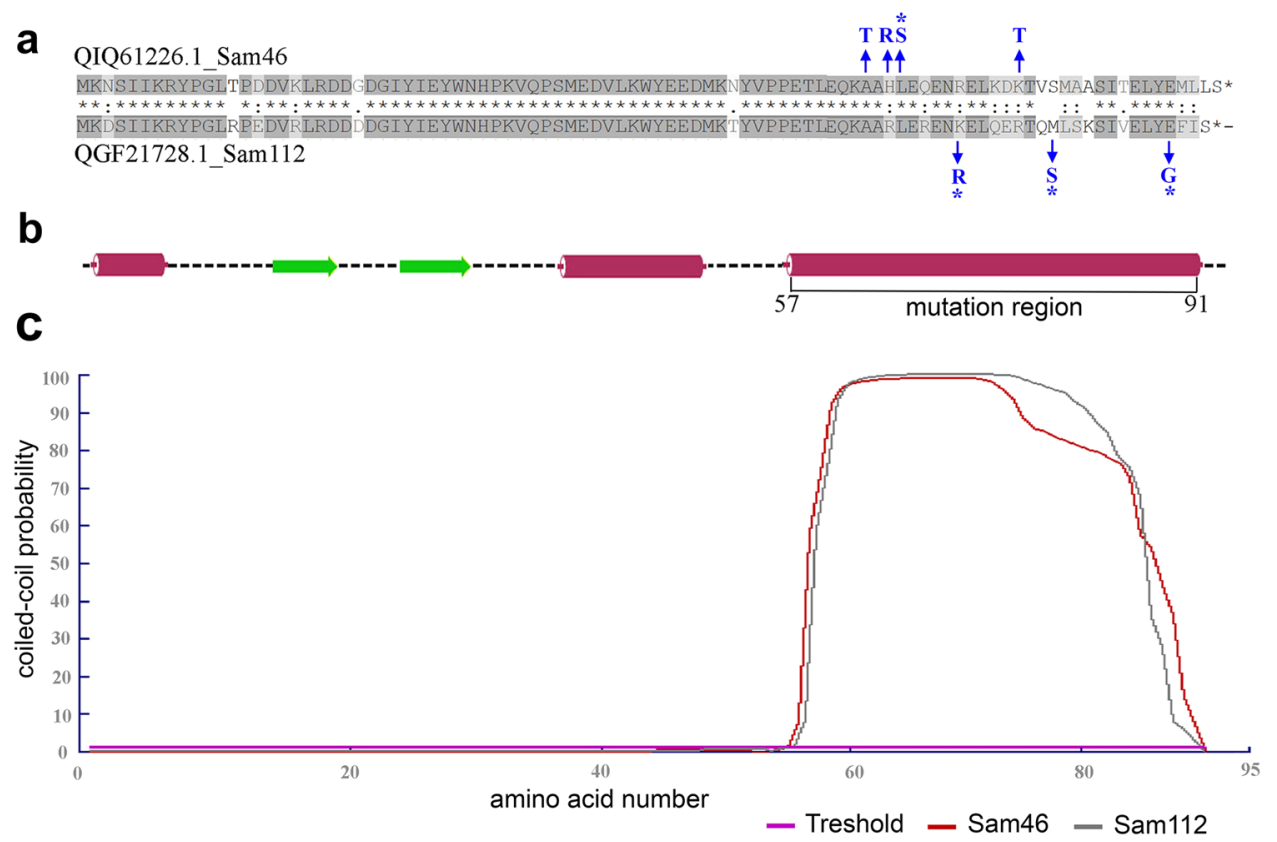

Figure 8. The sequence analysis of XkdW-like protein. (a) Sequence alignment of XkdW-like proteins of phage Sam 46 and Sam 112 by MAFFT version 7 (https://mafft.cbrc.jp/alignment/server). Accession numbers are labeled for each sequence. The mutations obtained from WGS data analysis are indicated in blue and the mutations found in Sanger sequencing data are indicated in blue with asterisks. (b) Secondary structure prediction for the XkdW-like protein of Sam46 by JPRED4 (http://www.compbio.dundee.ac.uk/jpred/) ( $\beta$-sheet: green arrow; $\alpha$-helix: burgundy block). C-terminal $\alpha$-helix is the mutation region. (c) Coiled-coil probability plotted versus the amino acid sequence of the XkdW-like protein of Sam46 and Sam112. The probabilities were determined using the LOGICOIL server (http://coiledcoils.chm.bris.ac.uk/LOGICOIL/).

Phage immunity test. As has been mentioned above, the difference between the Sam46-C and Sam46-T plaque morphotypes (Supplementary Information, Fig. S1), as well as the difference between the rates of $B$. cereus VKM B-370 lysis (Fig. 10) upon Sam46-T and Sam46-C infection, may be related to the formation of lysogens. Temperate phages, in the prophage stage, are known to make the host bacterium resistant to viruses identical or closely related to the prophages. This phenomenon is a special case of what is known as 'superinfection exclusion' 68,69 and is widely used to detect the presence of prophages.

To assess the immunity of B. cereus VKM B-370 cells collected from the centre of five turbid plaques (putative lysogens) against Sam46-T and Sam46-C infection, the cells were infected with Sam46-T or Sam46-C, as described in "Materials and methods". The optical density (OD595) of the cultures was measured upon the infection, and the measurement was performed three times for both the original B. cereus VKM B-370 cells and the putative phage-immune cells. As is shown in Fig. 11, the optical density of the putative phage-immune B. cereus VKM B-370 cultures decreased similarly to that of the original B. cereus VKM B-370 strain.

Thus, the appearance of Sam 46 and Sam 112 plaques with different morphotypes and the difference in the rate of B. cereus VKM B-370 lysis upon T-type and C-type phage infections are not associated with the formation of lysogens.

In view of the above and considering the fact that no genes typical of temperate phages have been found in the Sam46 and Sam112 genomes (see "General genome organization of Sam46 and Sam112"), it can be concluded that the phages are virulent.

Adsorption assay. An adsorption assay was performed to identify the rate at which the Sam46-T and Sam46-C phages are adsorbed to the cell surface of B. cereus VKM B-370. As shown in Fig. 12, a, the adsorption rates of Sam46-T and Sam46-C are highly similar: about $50 \%$ and $80 \%$ of the phages attach to the host cells within 10 and $20 \mathrm{~min}$, respectively. The adsorption rates of Sam46-T and Sam46-C are $9.68 \pm 0.36 \times 10^{-10} \mathrm{ml} /$ min and $9.20 \pm 0.20 \times 10^{-10} \mathrm{ml} / \mathrm{min}$, respectively.

One-step growth curve. The growth kinetics of Sam46-T and Sam46-C was determined by the one-step growth curve method. The latent period of both Sam46-T and Sam46-C is about $20 \mathrm{~min}$ and the duration of one lytic cycle is $15-20 \mathrm{~min}$. The burst size was found to be $450.5 \pm 70.5 \mathrm{PFU}$ and $565.6 \pm 64.6 \mathrm{PFU}$ per infected cell for Sam46-T and Sam46-C, respectively (Fig. 12b). 

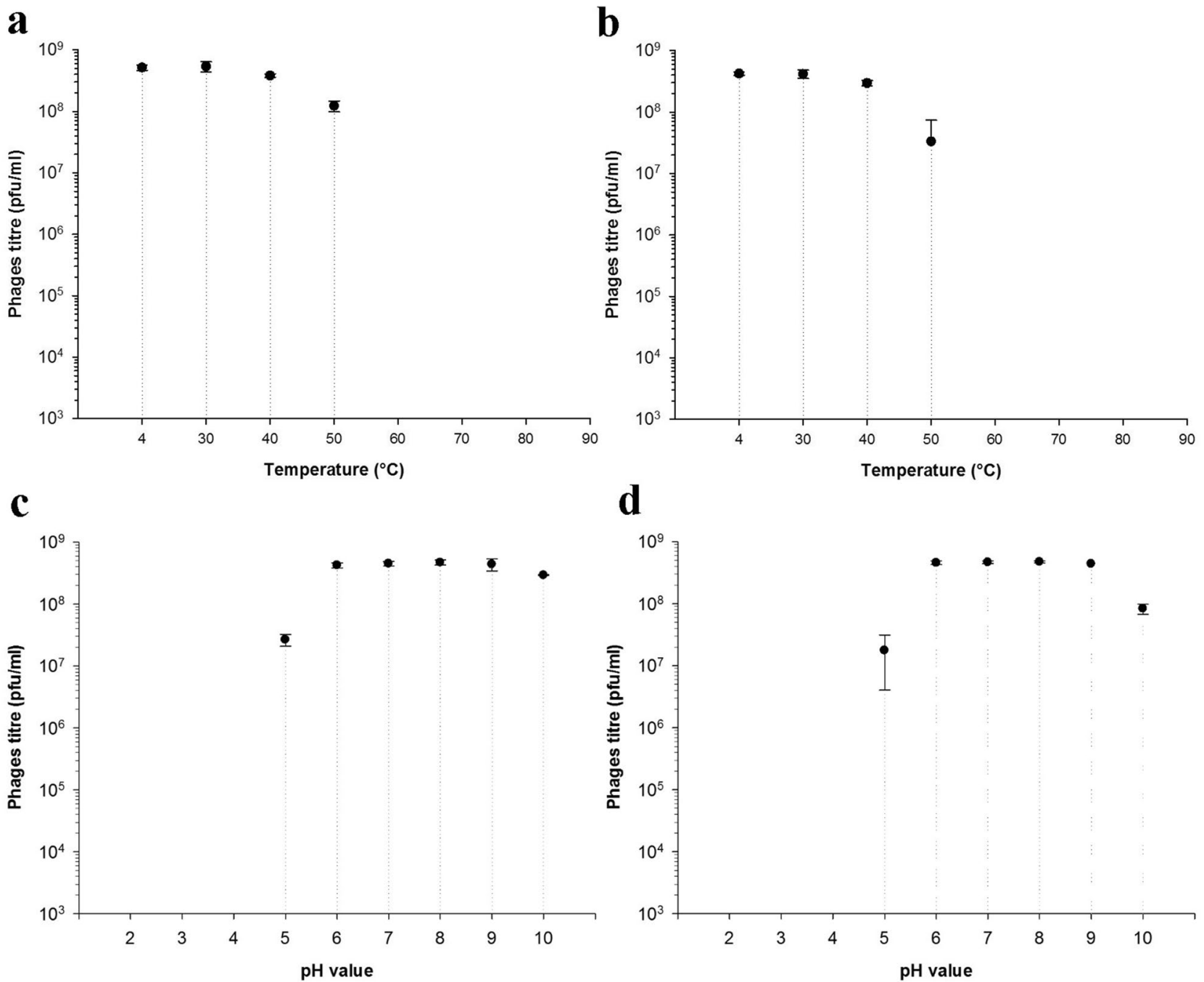

Figure 9. Thermal stability of the (a) Sam46-T and (b) Sam46-C phages. pH stability of the (c) Sam46-T and (d) Sam46-C phages. The graphs was created with SigmaPlot v.12.5 (http://www.sigmaplot.co.uk/products/ sigmaplot/produpdates/prod-updates18.php). Error bars represent standard deviation for three replicates.
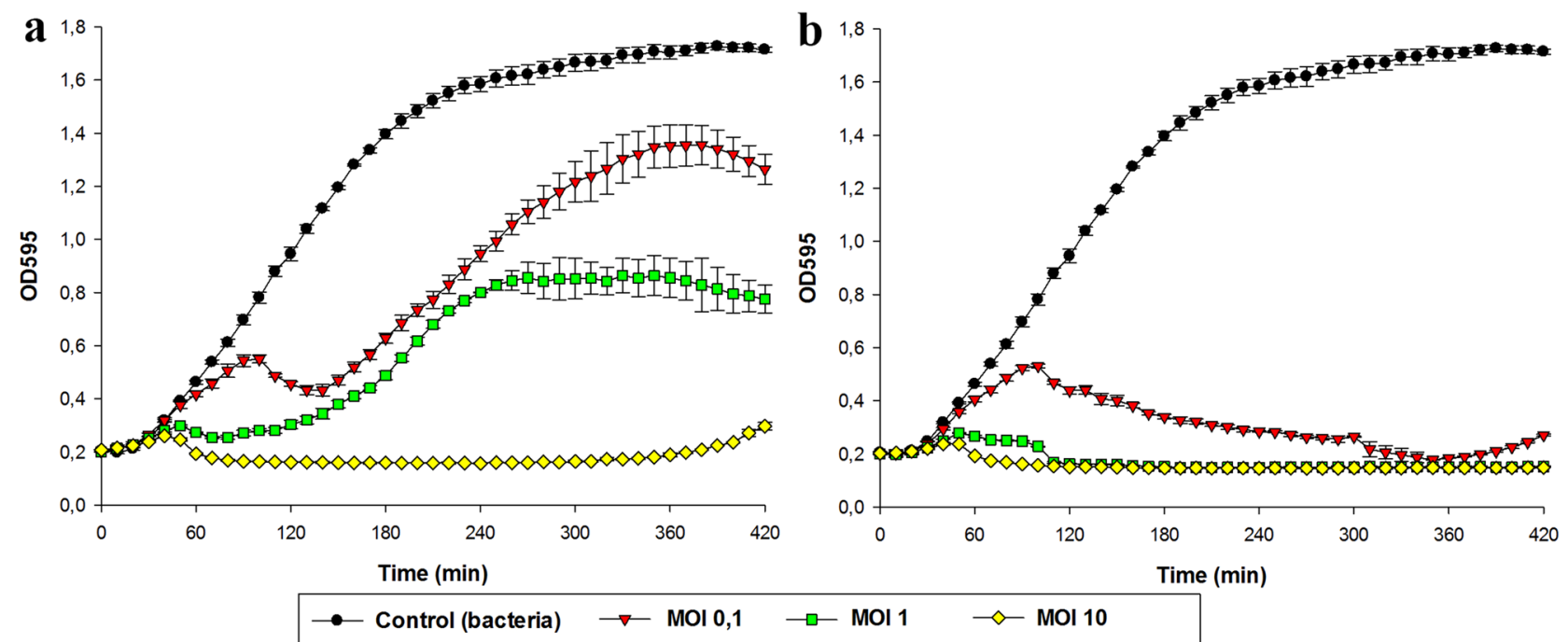

Figure 10. B. cereus VKM B-370 growth kinetics upon the infection with the (a) Sam46-T and (b) Sam46-C phages with different multiplicity of infection. Non-infected B. cereus VKM B-370 culture was used as a control. The graphs was created with SigmaPlot v.12.5 (http://www.sigmaplot.co.uk/products/sigmaplot/produpdates/ prod-updates18.php). Error bars represent standard deviation of the means for three replicates. 
a

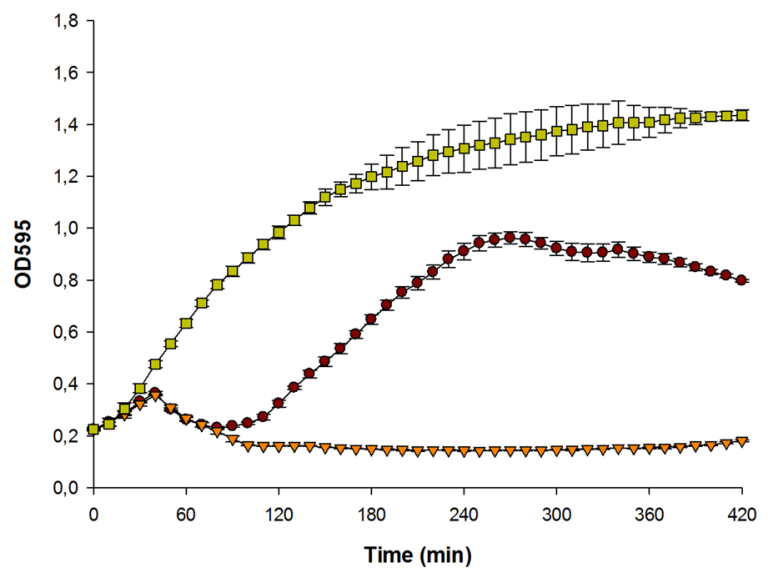

C

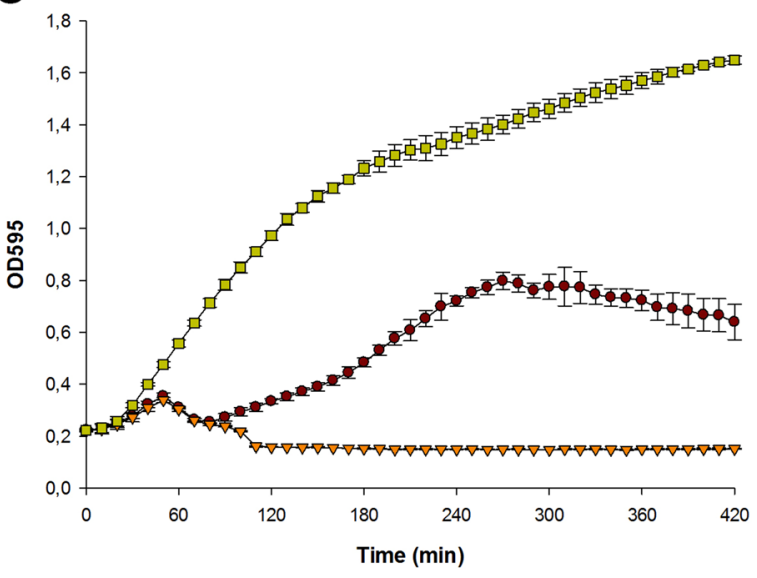

e

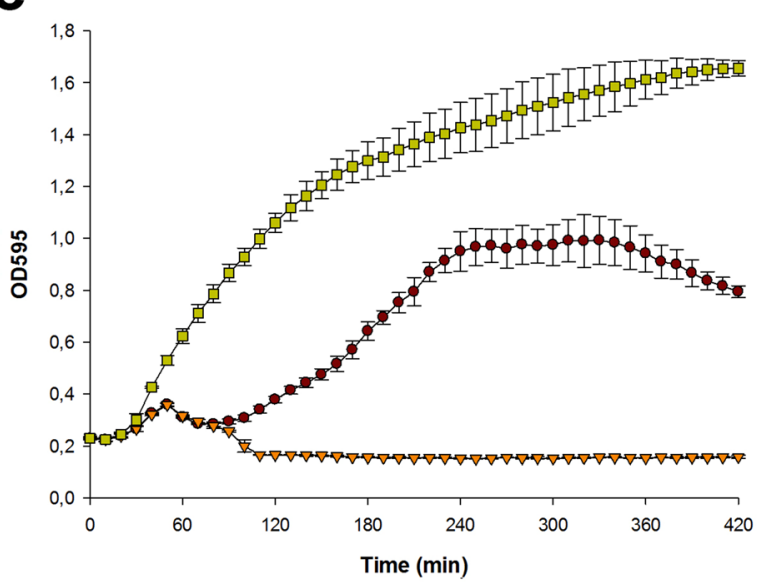

b

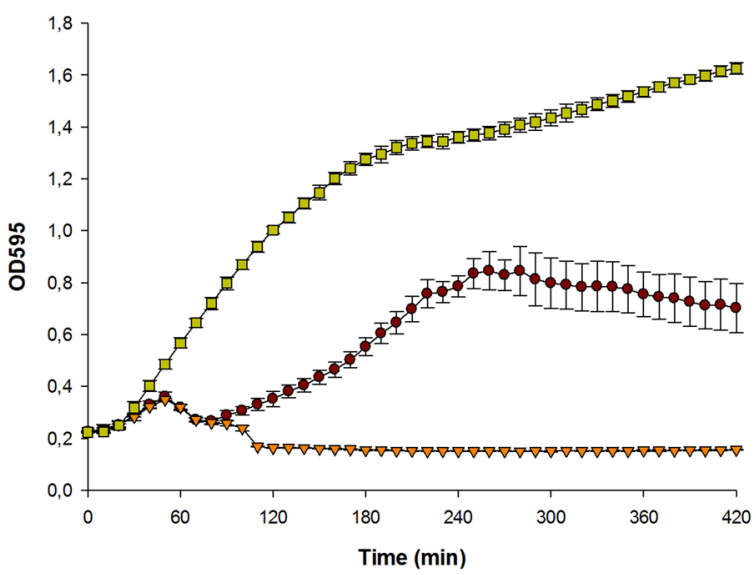

d

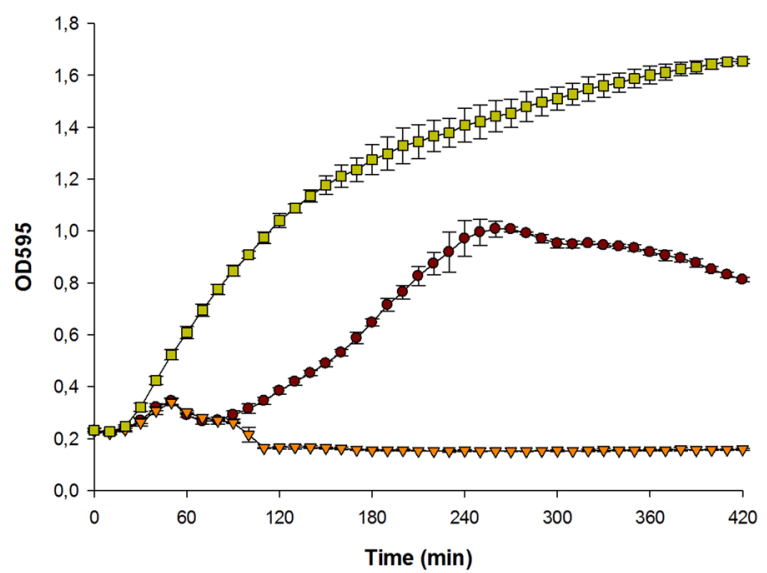

f

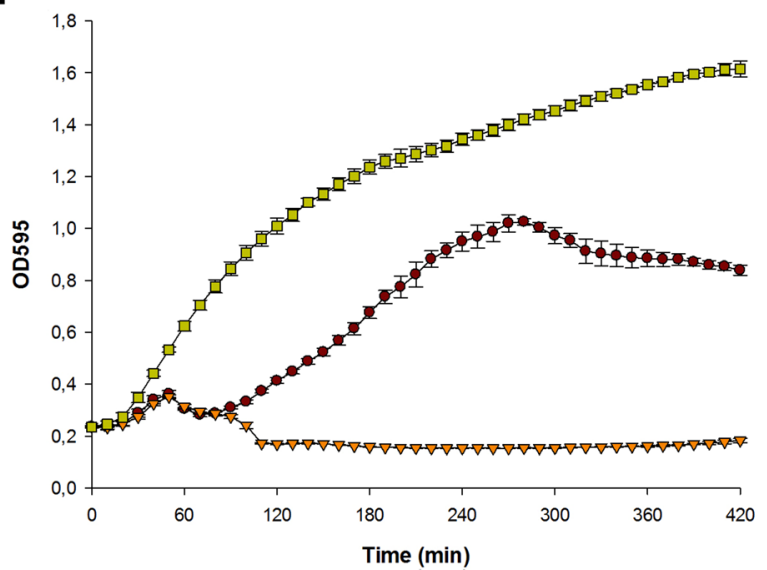

\section{$\multimap-$ No infection $\rightarrow$ Sam46-T infection $\quad \longrightarrow$ Sam46-C infection}

Figure 11. Growth kinetics of the putative phage-immune B. cereus VKM B-370 cultures upon the infection with the Sam46-T and Sam46-C phages. The measurement was carried out in the original B. cereus VKM B-370 strain used as (a) the control and (b-f) five cultures of the putative lysogenized cells collected from the central part of five separate turbid plaques formed by the Sam46-T phage. The graphs was created with SigmaPlot v.12.5 (http://www.sigmaplot.co.uk/products/sigmaplot/produpdates/prod-updates18.php). Error bars represent standard deviation of the means for three replicates. 

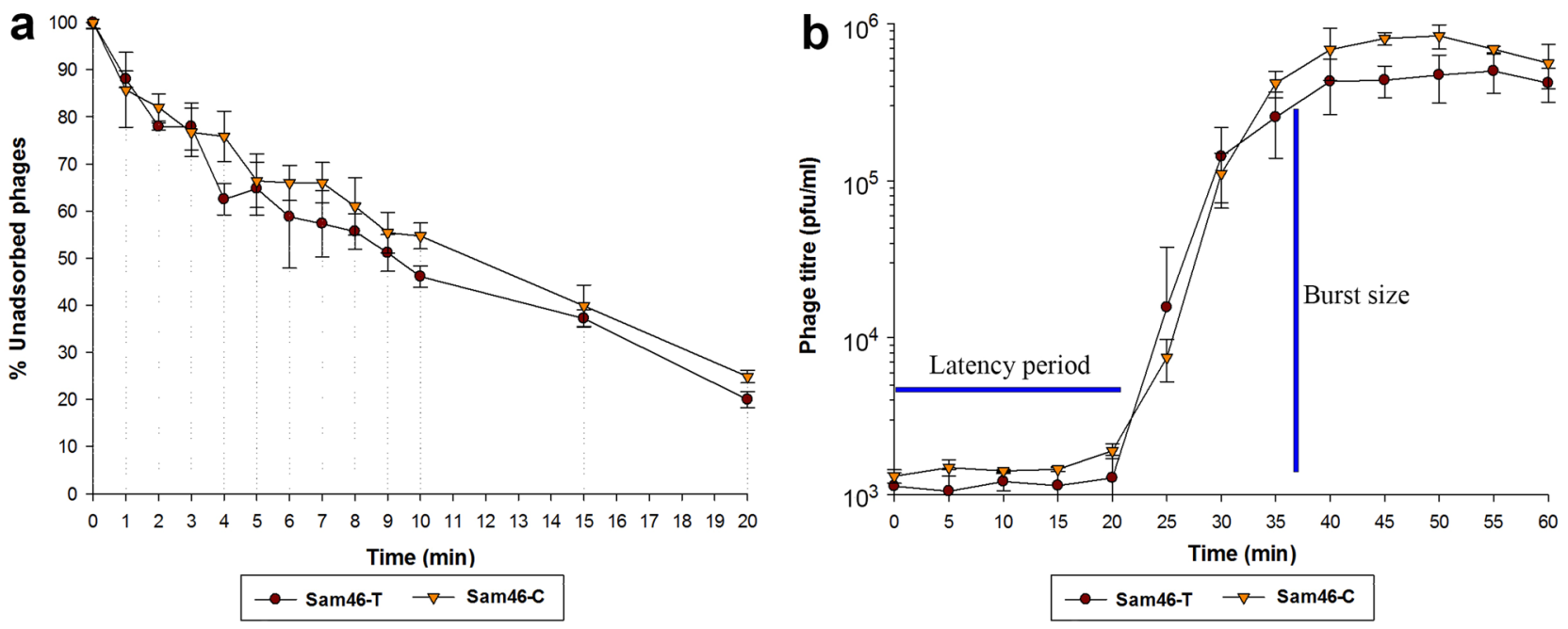

Figure 12. (a) Adsorption assay and (b) Growth parameters of the Sam46-T and Sam46-C phages. The graphs was created with SigmaPlot v.12.5 (http://www.sigmaplot.co.uk/products/sigmaplot/produpdates/prod-updat es18.php). Error bars represent standard deviation for three replicates.

\section{Discussion}

In this study, we have isolated and characterized new virulent bacteriophages Sam 46 and Sam112 with a lytic activity against the Bacillus cereus group. According to the morphological analysis, these phages have the myovirus morphotype. The genomes of Sam 46 and Sam 112 contain dsDNA with the length of 45,419 bp and 45,037 bp, respectively, and the same GC-content of 41.6\%. Phages Sam46 and Sam 112 have a high level of the whole genome nucleotide identity $(96.0 \%)$ indicating that they belong to the same phage species ${ }^{53}$.

Both Sam46 and Sam 112 were able to form two types of plaques: clear (C-type) and turbid (T-type) on the lawn of the host strain B. cereus VKM B-370. The purified C-type and T-type phages were able to stably produce uniform plaques in the following generations. As has been shown, the appearance of Sam 46 and Sam 112 plaques with different morphotypes and the difference in the rate of B. cereus VKM B-370 lysis upon T-type and C-type phage infections are not associated with the formation of lysogens (Fig. 11). The genome-wide analysis of C-type and T-type Sam46 phages suggests that the phenotypic difference of plaques is due to mutations in the gp25 gene encoding the XkdW-like protein with unknown function. The structural analysis of the XkdW-like protein showed that the detected mutations were located in the coiled-coil sequence (Fig. 8). The coiled-coil motifs are found in numerous protein structures including phage structural proteins such as fibritin (gpwac) of bacteriophage $\mathrm{T} 4^{70,71}$ and the distal subunit of the long tail fiber (gp37) ${ }^{72}$ of bacteriophage T4. The coiledcoil regions of such phage proteins proved to be crucial for the folding of the proteins, as well as for promoting conformational changes and contributing to protein-protein interactions ${ }^{70-72}$. Based on our experimental data and taking into account the gp25 gene neighboring tail-related genes (gp24, gp26), as well as considering the structural features of the $\mathrm{XkdW}$-like protein it encodes, we suggest that the gp25 product is apparently involved in phage tail assembly. With this in mind, the XkdW-like protein may be related to phage adsorption or may affect characteristics of the virion assembly such as the rate of assembly and the number of active phage particles. Different adsorption rates of T-type and C-type phages would explain the phenomenon of morphologically different plaques. However, the adsorption assay did not lend credence to this hypothesis. As shown in Fig. 12 a, about $80 \%$ of the Sam $46-\mathrm{T}$ and Sam $46-\mathrm{C}$ particles are adsorbed to the host cells within 20 min, with the rates of adsorption being $9.68 \pm 0.36 \times 10^{-10} \mathrm{ml} / \mathrm{min}$ and $9.20 \pm 0.20 \times 10^{-10} \mathrm{ml} / \mathrm{min}$, respectively. According to the results of the one-step growth curve experiment, the burst sizes of the Sam46-T and Sam46-C phages are slightly different: approximately $450.5 \pm 70.5 \mathrm{PFU}$ and $565.6 \pm 64.6 \mathrm{PFU}$ per infected cell, respectively. Thus, more detailed studies are needed for clear understanding of the XkdW-like protein function and its role in the Sam46 and Sam 112 lifecycles.

The thermal and $\mathrm{pH}$ stability of Sam46-T and Sam46-C were determined. Both Sam46-T and Sam46-C phages are stable at the temperatures ranging from 4 to $50{ }^{\circ} \mathrm{C}$, and a further increase in temperature $\left(60{ }^{\circ} \mathrm{C}\right.$ and higher) results in the complete inactivation of the phages (Fig. 9a,b). Almost 100\% of both Sam46-T and Sam46$\mathrm{C}$ phages survived at $\mathrm{pH}$ values ranging from 5 to 10, but neither phage survived at $\mathrm{pH} 2.2,3$ and 4 (Fig. 9c,d).

The predicted headful DNA packaging mechanism of Sam 46 and Sam 112 was experimentally confirmed by restriction analysis (Fig. 7b). We also determined the pac-site location using the method RAGE ${ }^{48}$ followed by Sanger sequencing (Fig. 7c).

An interesting feature of the Sam 46 and Sam 112 phages is the unusual structure of their small terminase subunit initiating DNA packaging. The small terminase subunit of these phages possesses a two-domain structure with the typical C-terminal Terminase_2 domain (residues 107-230) and N-terminal FtsK_gamma domain (residues 11-70); the latter has not been previously described as part of the small terminase subunit. Some phage genomes have been shown to contain genes encoding FtsK_gamma-like proteins, the role of which is still unclear. FtsK_gamma domain is a well-studied component of bacterial motor proteins such as the FtsK protein of $E$. 
coli and the SpoIIIE protein of B. subtilis, which are required to segregate DNA across bacterial membranes ${ }^{55,59}$. The FtsK_gamma domain recognizes and binds the octameric asymmetric sequences known as KOPS (FtsK Orienting Polarized Sequences) ${ }^{55}$ or FRS (FtsK Recognition Sequence), which in the case of SpoIIIE are known as SRS (SpoIIIE Recognition Sequence) ${ }^{59}$. On the one hand, such atypical domain structure of the small terminase indicates that the Sam 46 and Sam 112 genomes may contain KOPS/SRS-like binding sites, which act as recognizing and loading sites for the terminal complex and are likely to provide an oriented DNA translocation into procapsid. On the other hand, the FtsK_gamma domains of Sam46 and Sam112 are closely related to the FtsK_gamma domains of B. cereus and B. subtilis according to the phylogenetic analysis. This fact suggests that the small terminase can bind the SRS-sites of host DNA, resulting in the mispacking of bacterial DNA, instead of viral DNA, into their empty proheads. The majority of phages able to perform generalized transduction have been shown to package their DNA by the headful packaging mechanism ${ }^{73,74}$, in particular, the virulent Bacillus bacteriophage SPP1. The SPP1 phage is one of the closest relatives of the Sam 46 and Sam 112 phages according to the phylogenetic analysis (Figs. 4,5 ) and is able to encapsidate chromosomal or plasmid DNA ${ }^{74,75}$. Generalized transduction has been well-known to require that homologous regions or pseudo-pac sites be presented in the host chromosomal or plasmid DNA, in order for the host DNA to be mistakenly recognized by phage terminases. Furthermore, SPP1 replication and recombination systems have recently been shown to contribute to horizontal plasmid transfer, although to a different extent ${ }^{75}$. We have also found that the module of replication- and recombination-related genes of Sam 46 and Sam 112 resembles that of SPP1 (Fig. 6). Thus, we suppose that Sam 46 and Sam 112 are apparently generalized transducing phages. However, the structural characteristics of the small terminase subunit of Sam 46 and Sam 112 and its possible role in horizontal gene transfer need further studies.

According to the phylogenetic analysis, Sam 46 and Sam 112 form a distinct clade located at a considerable distance from the most closely related phages, SPP1 and D6E (Figs. 4, 5). We therefore infer that Sam 46 and Sam 112 may be the members of a new phage genus, and we propose to create a new phage genus called 'Samaravirus' to formally classify these phages.

Received: 24 October 2020; Accepted: 25 May 2021

Published online: 09 June 2021

\section{References}

1. Comeau, A. M. et al. Exploring the prokaryotic virosphere. Res. Microbiol. 195, 306-313. https://doi.org/10.1016/j.resmic.2008. 05.001 (2008).

2. Yau, S. \& Seth-Pasricha, M. Viruses of polar aquatic environments. Viruses 11, 189. https://doi.org/10.3390/v11020189 (2019).

3. Surgucheva, N. A. et al. Phage particles in ground arctic ice. Microbiology 88, 206-211. https://doi.org/10.1134/S00262617190201 64 (2019).

4. Castelan-Sanchez, H. G. et al. Extremophile deep-sea viral communities from hydrothermal vents. Structural and functional analysis. Mar. Genom. 46, 16-28. https://doi.org/10.1016/j.margen.2019.03.001 (2019).

5. Van Zyl, L. J. et al. Three novel bacteriophages isolated from the east African rift valley soda lakes. Virol. J. 13, 204. https://doi.org/ 10.1186/s12985-016-0656-6 (2016)

6. Weitz, J. S. \& Wilhelm, S. W. Ocean viruses and their effects on microbial communities and biogeochemical cycles. F1000 Biol. Rep.https://doi.org/10.3410/B4-17 (2012).

7. Coutinho, F. H. et al. New viral biogeochemical roles revealed through metagenomic analysis of lake Baikal. bioRxivhttps://doi. org/10.1186/s40168-020-00936-4) (2020).

8. Bi, L. et al. Diversity and potential biogeochemical impacts of viruses in bulk and rhizosphere soils. Environ. Microbiol.https://doi. org/10.1111/1462-2920.15010 (2020)

9. Chiang, Y. N., Penadés, J. R. \& Chen, J. Genetic transduction by phages and chromosomal islands: The new and noncanonical. PLoS Pathog.https://doi.org/10.1371/journal.ppat.1007878 (2019).

10. Chen, J. et al. Genome hypermobility by lateral transduction. Science 362, 207-212. https://doi.org/10.1126/science.aat5867 (2018).

11. O'Flaherty, S., Ross, R. P. \& Coffey, A. Bacteriophage and their lysins for elimination of infectious bacteria. FEMS Microbiol. Rev. 33, 801-819. https://doi.org/10.1111/j.1574-6976.2009.00176.x (2009).

12. Henry, M. \& Debarbieux, L. Tools from viruses: Bacteriophage successes and beyond. Virology 434, 151-161. https://doi.org/10. 1016/j.virol.2012.09.017 (2012).

13. O'Sullivan, L. et al. Bacteriophage-based tools: Recent advances and novel applications. F1000Researchhttps://oi.org/10.12688/ f1000research.9705.1 (2016).

14. Elbreki, M. et al. Bacteriophages and their derivatives as biotherapeutic agents in disease prevention and treatment. J. Viruseshttps:// doi.org/10.1155/2014/382539 (2014).

15. Brown-Jaque, M., Calero-Caceres, W. \& Muniesa, M. Transfer of antibiotic-resistance genes via phage-related mobile elements. Plasmid 79, 1-7. https://doi.org/10.1016/j.plasmid.2015.01.001 (2015).

16. Brussow, H., Canchaya, C. \& Hardt, W. D. Phages and the evolution of bacterial pathogens. From genomic rearrangements to lysogenic conversion. Microbiol. Mol. Biol. Rev. 68, 560-602. https://doi.org/10.1128/MMBR.68.3.560-602.2004 (2004).

17. Canchaya, C. et al. Phage as agents of lateral gene transfer. Curr. Opin. Microbiol. 6, 417-424. https://doi.org/10.1016/S13695274(03)00086-9 (2003).

18. Carlson, C. J. et al. The global distribution of Bacillus anthracis and associated anthrax risk to humans, livestock and wildlife from genomic rearrangements to lysogenic conversion. Nat. Microbiol. 4, 1337-1343. https://doi.org/10.1038/s41564-019-0435-4 (2019).

19. Granum, P. E. \& Lund, T. Bacillus cereus and its food poisoning toxins. FEMS Microbiol. Lett. 157, 223-228. https://doi.org/10. 1111/j.1574-6968.1997.tb12776.x (1997).

20. Guinebretiere, M. H. et al. Bacillus cytotoxicus sp nov. is a novel thermotolerant species of the Bacillus cereus group occasionally associated with food poisoning. Int. J. Syst. Evol. Microbiol. 63, 31-40. https://doi.org/10.1099/ijs.0.030627-0 (2013).

21. Lund, T., De Buyser, M. L. \& Granum, P. E. A new cytotoxin from Bacillus cereus that may cause necrotic enteritis. Mol. Microbiol. 38, 254-261. https://doi.org/10.1046/j.1365-2958.2000.02147.x (2000).

22. Vachon, V., Laprade, R. \& Schwartz, J. L. Current models of the mode of action of Bacillus thuringiensis insecticidal crystal proteins: a critical review. J. Invertebr. Pathol. 111, 1-12. https://doi.org/10.1016/j.jip.2012.05.001 (2012).

23. Sanchis, V. \& Bourguet, D. Bacillus thuringiensis: Applications in agriculture and insect resistance management. Agron. Sustain. Dev. 28, 11-20. https://doi.org/10.1051/agro:2007054 (2008). 
24. Koch, M. S. et al. The food and environmental safety of Bt crops. Front. Plant Sci. 6, 283. https://doi.org/10.3389/fpls.2015.00283 (2015).

25. Johler, S. et al. Enterotoxin production of Bacillus thuringiensis isolates from biopesticides, foods, and outbreaks. Front. Microbiol. 9, 1915. https://doi.org/10.3389/fmicb.2018.01915 (2018).

26. Raymond, B. \& Federici, B. A. In defence of Bacillus thuringiensis, the safest and most successful microbial insecticide available to humanity - a response to EFSA. FEMS Microbiol. Ecol. 93, fix084. https://doi.org/10.1093/femsec/fix084 (2017).

27. Fenselau, C. et al. Identification of $\beta$-Lactamase in antibiotic-resistant Bacillus cereus spores. Appl. Environ. Microbiol. 74, 904-906. https://doi.org/10.1128/AEM.00788-07 (2008).

28. Owusu-Kwarteng, J. et al. Prevalence, virulence factor genes and antibiotic resistance of Bacillus cereus sensu lato isolated from dairy farms and traditional dairy products. Bmc Microbiol. 17, 65. https://doi.org/10.1186/s12866-017-0975-9 (2017).

29. Piligrimova, E. G. et al. Bacillusphage vB \_BtS\_B83 previously designated as a plasmid may represent a new Siphoviridae genus. Viruses 11, 624. https://doi.org/10.3390/v11070624 (2019).

30. Sambrook, J., Fritsch, E. F. \& Maniatis, T. Molecular Cloning: A Laboratory Manual (Cold Spring Harbor Laboratory Press, 1989).

31. Bankevich, A. et al. SPAdes: A new genome assembly algorithm and its applications to single-cell sequencing. J. Comput. Biol 19, 455-477. https://doi.org/10.1089/cmb.2012.0021 (2012).

32. Brettin, T. et al. RASTtk: A modular and extensible implementation of the RAST algorithm for building custom annotation pipelines and annotating batches of genomes. Sci. Rep. 5, 8365. https://doi.org/10.1038/srep08365 (2015).

33. Altschul, S. F. et al. Basic local alignment search tool. J. Mol. Biol. 215, 403-410. https://doi.org/10.1016/S0022-2836(05)80360-2 (1990).

34. Soding, J., Biegert, A. \& Lupas, A. N. The HHpred interactive server for protein homology detection and structure prediction. Nucleic Acids Res. 33, 244-248. https://doi.org/10.1093/nar/gki408 (2005).

35. Alikhan, N. F. et al. BLAST Ring Image Generator (BRIG): Simple prokaryote genome comparisons. BMC Genom. 12, 402. https:// doi.org/10.1186/1471-2164-12-402 (2011).

36. Katoh, K. \& Standley, D. M. MAFFT multiple sequence alignment software version 7: Improvements in performance and usability. Mol. Biol. Evol. 30, 772-780. https://doi.org/10.1093/molbev/mst010 (2013).

37. Huson, D. H. \& Bryant, D. Application of phylogenetic networks in evolutionary studies. Mol. Biol. Evol. 23, 254-267. https://doi. org $/ 10.1093 / \mathrm{molbev} / \mathrm{msj} 030$ (2006).

38. Nishimura, Y. et al. ViPTree: The viral proteomic tree server. Bioinformatics 33, 2379-2380. https://doi.org/10.1093/bioinforma tics/btx157 (2017)

39. Contreras-Moreira, B. \& Vinuesa, P. GET\HOMOLOGUES, a versatile software package for scalable and robust microbial pangenome analysis. Appl. Environ. Microbiol. 79, 7696-7701. https://doi.org/10.1128/AEM.02411-13 (2013).

40. Kristensen, D. M. et al. A low-polynomial algorithm for assembling clusters of orthologous groups from intergenomic symmetric best matches. Bioinformatics 26, 1481-1487. https://doi.org/10.1093/bioinformatics/btq229 (2010).

41. Vinuesa, P., Ochoa-Sanchez, L. E. \& Contreras-Moreira, B. GET\_PHYLOMARKERS, a software package to select optimal orthologous clusters for phylogenomics and inferring pan-genome phylogenies, used for a critical geno-taxonomic revision of the genus Stenotrophomonas. Front. Microbiol. 9, 771. https://doi.org/10.3389/fmicb.2018.00771 (2018).

42. Sullivan, M. J., Petty, N. K. \& Beatson, S. A. Easyfig: A genome comparison visualizer. Bioinformatics 27, 1009-1010. https://doi. org/10.1093/bioinformatics/btr039 (2011).

43. Li, S. et al. Scrutinizing virus genome termini by high-through put sequencing. PLoS One 9, e85806. https://doi.org/10.1371/journ al.pone.0085806 (2014).

44. Zhang, X., Wang, Y. \& Tong, Y. Analyzing Genome Termini of Bacteriophage Through High-Throughput Sequencing. Methods in Molecular Biology (Humana Press, 2018).

45. Langmead, B. Aligning short sequencing reads with bowtie. Curr. Protoc. Bioinform. 32, 11-17. https://doi.org/10.1002/04712 50953.bil107s32 (2010).

46. Langmead, B. \& Salzberg, S. L. Fast gapped-read alignment with Bowtie 2. Nat. Methods 9, 357. https://doi.org/10.1038/nmeth. 1923 (2012).

47. Casjens, S. R. \& Gilcrease, E. B. Determining DNA Packaging Strategy by Analysis of the Termini of the Chromosomes in TailedBacteriophage Virions. Methods in Molecular Biology Vol. 502 (Humana Press, 2009).

48. Cormack, R. S. \& Somssich, I. Rapid amplification of genomic ends (RAGE) as a simple method to clone flanking genomic DNA. Gene 194, 273-276. https://doi.org/10.1016/S0378-1119(97)00205-9(1997).

49. Drozdetskiy, A. et al. Jpred4: A protein secondary structure prediction server. Nucleic Acids Res. 43, W389-W394. https://doi.org/ 10.1093/nar/gkv332 (2015).

50. Vincent, T. L., Green, P. J. \& Woolfson, D. N. LOGICOIL-multi-state prediction of coiled-coil oligomeric state. Bioinformatics 29, 69-76. https://doi.org/10.1093/bioinformatics/bts648 (2013).

51. Kropinski, A. M. Measurement of the rate of attachment of bacteriophage to cells. In Bacteriophages 151-155 (Springer, 2009).

52. Hyman, P. \& Abedon, S. T. Practical methods for determining phage growth parameters. In Bacteriophages 175-202 (Springer, 2009).

53. Adriaenssens, E. \& Brister, J. R. How to name and classify your phage: An informal guide. Viruses 9, 70. https://doi.org/10.3390/ v9040070 (2017)

54. Turner, D., Kropinski, A. M. \& Adriaenssens, E. M. A roadmap for genome-based phage taxonomy. Viruses 13, 506. https://doi. org/10.3390/v13030506 (2021).

55. Lowe, J. et al. Molecular mechanism of sequence-directed DNA loading and translocation by FtsK. Mol. Cell 31, 498-509. https:// doi.org/10.1016/j.molcel.2008.05.027 (2008).

56. Bigot, S. et al. FtsK, a literate chromosome segregation machine. Mol. Microbiol. 64, 1434-1441. https://doi.org/10.1111/j.13652958.2007.05755.x (2007).

57. Nolivos, S. et al. KOPS: DNA motifs that control E. coli chromosome segregation by orienting the FtsK translocase. EMBO J. 24, 3770-3780. https://doi.org/10.1038/sj.emboj.7600835 (2005).

58. Nolivos, S. et al. Co-evolution of segregation guide DNA motifs and the FtsK translocase in bacteria. Identification of the atypical Lactococcus lactis KOPS motif. Nucleic Acids Res. 40, 5535-5545. https://doi.org/10.1093/nar/gks171 (2012).

59. Ptacin, J. L. et al. Sequence-directed DNA export guides chromosome translocation during sporulation in Bacillus subtilis. Nat. Struct. Mol. Biol. 15, 485. https://doi.org/10.1038/nsmb.1412 (2008).

60. Sivanathan, V. et al. The FtsK $\gamma$ domain directs oriented DNA translocation by interacting with KOPS. Nat. Struct. Mol. Biol. 13, 965-972. https://doi.org/10.1038/nsmb1158 (2006).

61. Wang, Y. \& Zhang, X. Genome analysis of deep-sea thermophilic phage D6E. Appl. Environ. Microbiol. 76, 7861-7866. https://doi. org/10.1128/AEM.01270-10 (2010).

62. Weigel, C. \& Seitz, H. Bacteriophage replication modules. FEMS Microbiol. Rev. 30, 321-381. https://doi.org/10.1111/j.1574-6976. 2006.00015.x (2006).

63. Martínez-Jiménez, M. I., Alonso, J. C., \& Ayora, S. Bacillus subtilis Bacteriophage SPP1-encoded Gene 34.1 Product is a Recombination-dependent DNA Replication Protein. J Mol Biol. 351(5) 1007-1019. https://doi.org/10.1016/j.jmb.2005.06.064 (2005)

64. Ayora, S. et al. Homologous-pairing activity of the Bacillus subtilis bacteriophage SPP1 replication protein G35P. J. Biol. Chem. 277, 35969-35979. https://doi.org/10.1074/jbc.M204467200 (2002). 
65. Seco, E. M. et al. Bacteriophage SPP1 DNA replication strategies promote viral and disable host replication in vitro. Nucleic Acids Res. 41, 1711-1721. https://doi.org/10.1093/nar/gks1290 (2013).

66. Ackermann, H. W. Frequency of morphological phage descriptions in the year 2000. Adv. Virol. 146, 843-857. https://doi.org/10. 1007/s007050170120 (2001).

67. Lupas, A. N., Bassler, J. \& Dunin-Horkawicz, S. The Structure and Topology of $\alpha$-Helical Coiled Coils Vol. 82 (Springer, 2017).

68. Harrison, E. \& Brockhurst, M. A. Ecological and evolutionary benefits of temperate phage: What does or doesn't kill you makes you stronger. BioEssays 39, 1700112. https://doi.org/10.1002/bies.201700112 (2017).

69. Bondy-Denomy, J. et al. Prophages mediate defense against phage infection through diverse mechanisms. ISME J. 10, $2854-2866$. https://doi.org/10.1038/ismej.2016.79 (2016).

70. Tao, Y. et al. Structure of bacteriophage T4 fibritin: A segmented coiled coil and the role of the C-terminal domain. Structure 5, 789-798. https://doi.org/10.1016/S0969-2126(97)00233-5 (1997).

71. Letarov, A. et al. gpwac of the T4-type bacteriophages: Structure, function, and evolution of a segmented coiled-coil protein that controls viral infectivity. J. Bacteriol. 187, 1055-1066. https://doi.org/10.1128/JB.187.3.1055-1066.2005 (2005).

72. Qu, Y. et al. In vivo bypass of chaperone by extended coiled-coil motif in T4 tail fiber. J. Bacteriol. 186, 8363-8369. https://doi.org/ 10.1128/JB.186.24.8363-8369.2004 (2004).

73. Thierauf, A., Perez, G. \& Maloy, S. Generalized Transduction. Methods in Molecular Biology (Humana Press, 2009).

74. Yasbin, R. E. \& Young, F. E. Transduction in Bacillus subtilis by bacteriophage SPP1. J. Virol. 14, 1343-1348. https://doi.org/10. 1128/JVI.14.6.1343-1348.1974 (1974).

75. Valero-Rello, A. et al. Molecular mechanisms that contribute to horizontal transfer of plasmids by the bacteriophage SPP1. Front. Microbiol. 8, 1816. https://doi.org/10.3389/fmicb.2017.01816 (2017).

\section{Acknowledgements}

The authors would like to acknowledge Ryabova Natalya A. from Institute of Protein Research, Russian Academy of Sciences, for technical support and the results of TEM analysis and Zagorodniy Vladimir A., a student of Samara State University, for providing us with the soil samples collected in Samara, Russian Federation and for his help in phage isolation.

\section{Author contributions}

O.A.K., E.G.P. and A.M.S. conceived the project, O.A.K. conducted the experiments, O.A.K. and E.G.P. performed the computational analyses, O.A.K. and E.G.P. wrote the paper, A.M.S. acquired the grants, A.M.S. supervised the project. All authors reviewed the manuscript.

\section{Funding}

This research was funded by the Russian Foundation for Basic Research according to the research project (Grant number 19-04-00300) and by the Ministry of Science and Higher Education of the Russian Federation (state assignment number 075-03-2019-525/2 (AAAA-A19-119120390010-1)).

\section{Competing interests}

The authors declare no competing interests.

\section{Additional information}

Supplementary Information The online version contains supplementary material available at https://doi.org/ 10.1038/s41598-021-91289-x.

Correspondence and requests for materials should be addressed to O.A.K. or A.M.S.

Reprints and permissions information is available at www.nature.com/reprints.

Publisher's note Springer Nature remains neutral with regard to jurisdictional claims in published maps and institutional affiliations.

(c) (i) Open Access This article is licensed under a Creative Commons Attribution 4.0 International

License, which permits use, sharing, adaptation, distribution and reproduction in any medium or format, as long as you give appropriate credit to the original author(s) and the source, provide a link to the Creative Commons licence, and indicate if changes were made. The images or other third party material in this article are included in the article's Creative Commons licence, unless indicated otherwise in a credit line to the material. If material is not included in the article's Creative Commons licence and your intended use is not permitted by statutory regulation or exceeds the permitted use, you will need to obtain permission directly from the copyright holder. To view a copy of this licence, visit http://creativecommons.org/licenses/by/4.0/.

(c) The Author(s) 2021 